\title{
К вопросу об оптимальной микробиологической деконтаминации воздушной среды и поверхностей
}

\author{
Ю. А. Бошняга ${ }^{a^{*}}$, М. К. Болога ${ }^{a}$ Е. Ю. Агарвал ${ }^{\mathrm{b}}$ \\ ${ }^{a}$ Институт прикладной физики, \\ 2. Кишинев, МD-2028, Молдова \\ ${ }^{b}$ Теоретический лицей Н. Сулак, \\ 2. Кишинев, МD-2019, Молдова \\ "e-mail: iubosneaga@gmail.com \\ Поступила в редакцию 05.04.2021 \\ После доработки 03.12.2021 \\ Принята к публикации 07.12.2021
}

Современная цивилизация, обеспечивая экономический и социальный прогресс, одновременно объективно создает - подчас близкие к идеальным - условия для распространения разнообразных инфекций. Катастрофические последствия пандемии $S A R S-C o V-2$ однозначно свидетельствуют - homo sapiens оказался неспособным эффективно противостоять напору коронавируса. Цель данной публикации - попытка восполнить пробел в разработке эффективных методов и средств микробиологической деконтаминации, оптимальных по критическим параметрам. Данные наблюдений свидетельствуют, что значительное число заражений коронавирусом SARS-CoV-2 происходит воздушным путем без непосредственного контакта с источником, в том числе в продолжительном временном интервале. Атмосферные осадки способствуют очищению воздуха от загрязнений и вирусов, снижая бесконтактные заражения, что дополнительно актуализирует проблему оптимальной микробиологической деконтаминации воздушной среды и поверхностей. Для оптимизации микробиологической стерилизации применен термодинамический подход. Показано, что необратимые химические реакции окисления являются кратчайшим способом достижения стерильности, причем они способны обеспечить высокую надежность деконтаминации. Установлено, что кислород оптимален в качестве окислителя, в том числе экологически, поскольку его реакционно-активные формы гармонично вписываются в естественные циклы обмена. Оптимальным методом получения реакционно-активных форм кислорода для обеззараживания является применение низкотемпературной («холодной») плазмы, обеспечивающей энергоэффективную генерацию окислительных реакционно-активных форм, - атомарного кислорода $(\mathrm{O})$, озона $\left(\mathrm{O}_{3}\right)$, гидроксильного радикала $(\cdot \mathrm{OH})$, перекиси водорода $\left(\mathrm{H}_{2} \mathrm{O}_{2}\right)$, супероксида $\left(\mathrm{O}_{2}^{-}\right)$, синглетного кислорода $\mathrm{O}_{2}\left(a^{1} \Delta_{g}\right)$. Из-за короткого времени жизни большинства названных форм вне плазменного аппликатора удаленные от генератора плазмы объекты стерилизуются озоном $\left(\mathrm{O}_{3}\right)$, минимальное время жизни которого достаточно велико. Обосновано, что для энергоэффективного производства озона оптимальна микроволновая генерация кислородной плазмы. Для варьирования в широких пределах производительности установок генерирования озона предложен модульный принцип. Модуль разработан на базе адаптированной серийной микроволновой печи, в которой поддерживается несамостоятельный СВЧ-разряд благодаря ионизаторам (игнайтерам), в том числе на базе излучающих радионуклидов-эмиттеров. При массивном загрязнении поверхностей целесообразно - дополнительно к обеззараживающему воздух озону $\left(\mathrm{O}_{3}\right)$ - применение водных растворов перекиси водорода $\left(\mathrm{H}_{2} \mathrm{O}_{2}\right)$. Эти реакционно-активные формы кислорода для обеззараживания удаленных от генератора плазмы объектов обладают высокой эффективностью и экологически нейтральны. Предложены надежные и доступные средства индивидуальной защиты при нахождении в зонах повышенной концентрации озона. Рассмотренные оптимальные средства обеззараживания могут быть адаптированы для многочисленных применений в сельском хозяйстве, промышленности и в быту.

Ключевые слова: коронавирус, оптимизация микробиологической стерилизации, термодинамический подход, реакционно-активные формы кислорода, низкотемпературная плазма, озон, перекись водорода, микроволны

УдК 543.95; 533.9

https://doi.org/10.52577/eom.2021.57.6.87

\section{ОБ АКТУАЛЬНОСТИ ОПТИМИЗАЦИИ МИКРОБИОЛОГИЧЕСКОЙ ДЕКОНТАМИНАЦИИ}

В условиях роста населения Земли, его ускоренной урбанизации и беспрецедентной мобильности опасность возникновения и взрывоподобного распространения инфекций резко возрастает. Антропогенная деградация окружающей среды также способствует непрерывному обновлению (актуализации) микробиологических угроз. Экономический и социальный эффект от воздействия коронавируса SARS-CoV-2 (COVID-19) превзошел предыдущие эпидемии опасных заболеваний XXI века (атипичной пневмонии, Эболь, свиного $и$ 
птичьего грипnа). Молниеносному (по эпидемиологическим критериям) превращению отдельного очага в ужасающую пандемию способствовала не только недооценка вирулентности «свежего» коронавируса SARS-CoV-2, но также трактовка данной коронавирусной инфекции, главным образом, как «болезни грязных рук», результата прямого контакта с источником. Соответственно основной инструментарий предотвращения распространения инфекции - соблюдение личной гигиены, недопущение прямого контакта и ношение маски, а также распыление дезинфицирующих средств.

Опыт тем не менее показывает, что этими (весьма дорогостоящими) мерами остановить заражение коронавирусом SARS-CoV-2 не удается. Причина, по-видимому, состоит в том, что значительное число заражений происходит воздушным путем, обычно от неопределенного источника, а не в результате прямого (непосредственного) контакта. Это подтверждают многочисленные данные - как правило, заболевшие не могут установить, когда или где были инфицированы, хотя и соблюдали правила личной гигиены.

Статистика свидетельствует, что вероятность выживания вируса значительно увеличивается во влажных условиях по сравнению с сухими. Однако вирус $S A R S-C o V-2$ имеет защитный липидный слой (его белковая оболочка капсид выполняет функцию защиты генетического материала вируса - РНК - от механических, физических и химических повреждений), что позволяет ему лучше выживать в сложных условиях, в том числе при низкой относительной влажности. Полагаем, что коронавирусные частицы в составе воздушно-капельного аэрозоля, идущие от источника заражения, электростатически прикрепляются к пылинкам и другим содержащимся в воздухе частичкам коллоидного размера и (после вероятного обезвоживания и превращения в биополимеры) могут переноситься в таком «консервированном» виде на значительные расстояния. Данная версия подтверждается снижением уровней заражений после атмосферных осадков [1], очищающих воздух от мелкодисперсных примесей. Отметим, что обезвоженные (высушенные) вирусы представляют особую опасность в контексте их беспрепятственной миграции на большие расстояния. Живучесть таких вирусов объясняется их пониженной чувствительностью к дневному ультрафиолетовому излучению: фотоабсорбция ультрафиолета сухими вирусами не приводит к образованию производных от воды окисляющих радикалов $(\mathrm{OH}$ и О) - из-за отсутствия близлежащих молекул воды. В результате воздействие ультрафиолетового излучения на РНК и другие компоненты коронавируса без закрепляющего результат окисления оказывается малоэффективным. Этим объясняем беспрепятственное распространение коронавирусной инфекции при сухой, теплой и солнечной погоде - в Индии, Бразилии, США в 2020 году, а также в России - летом 2021 года. Проблема решается очисткой воздуха от загрязнений. Для открытых пространств это возможно с помощью атмосферных осадков, а для закрытых - применением адекватного окисления агентов заражения (см. ниже).

Фактор осадков заслуживает специального рассмотрения. На первый взгляд, осадки способны лишь усилить заражаемость - за счет поддержания повышенной влажности и умеренных температур.

Однако значительно более важным оказывается регулярное (периодическое) удаление из воздуха мелкодисперсных загрязнений, а вместе с ними - и вирусов. С этой задачей, как показали наши погодные наблюдения, хорошо справляются мелкие, моросящие, но непременно регулярные и существенной продолжительности дожди (при этом месячное количество осадков является второстепенным параметром). Такая уникальная (с точки зрения профилактики короновирусной инфекции) ситуация сложилась в Республике Молдова в апреле - мае 2021 года. На рис. 1 показана динамика снижения заражений коронавирусом в Республике Молдова в апреле - мае 2021 года - в увязке с периодическими моросящими (дробными) осадками. Заметим, что столь существенное падение числа инфицированных нельзя отнести на счет эффекта самоограничений из-за неблагоприятной погоды ( “stay at home effect”) напротив, при малом проценте вакцинированных, на этот период пришлось проведение массовых мероприятий, снижение (либерализация) эпидемиологических ограничений, возобновление очного обучения и т.д. С другой стороны, годом раньше - весной и летом 2020 года - на фоне необычайной засухи и полного отсутствия периодических моросящих осадков в Республике Молдова наблюдался прогрессивный рост числа заражений (причем несмотря на принимавшиеся противоэпидемические ограничения). Представленные данные являются косвенным доказательством того, что значительное число заражений коронавирусом SARS-CoV-2 происходит воздушным nутем, без прямого контакта с источником. Дополнительно уместно упомянуть (опублико- 


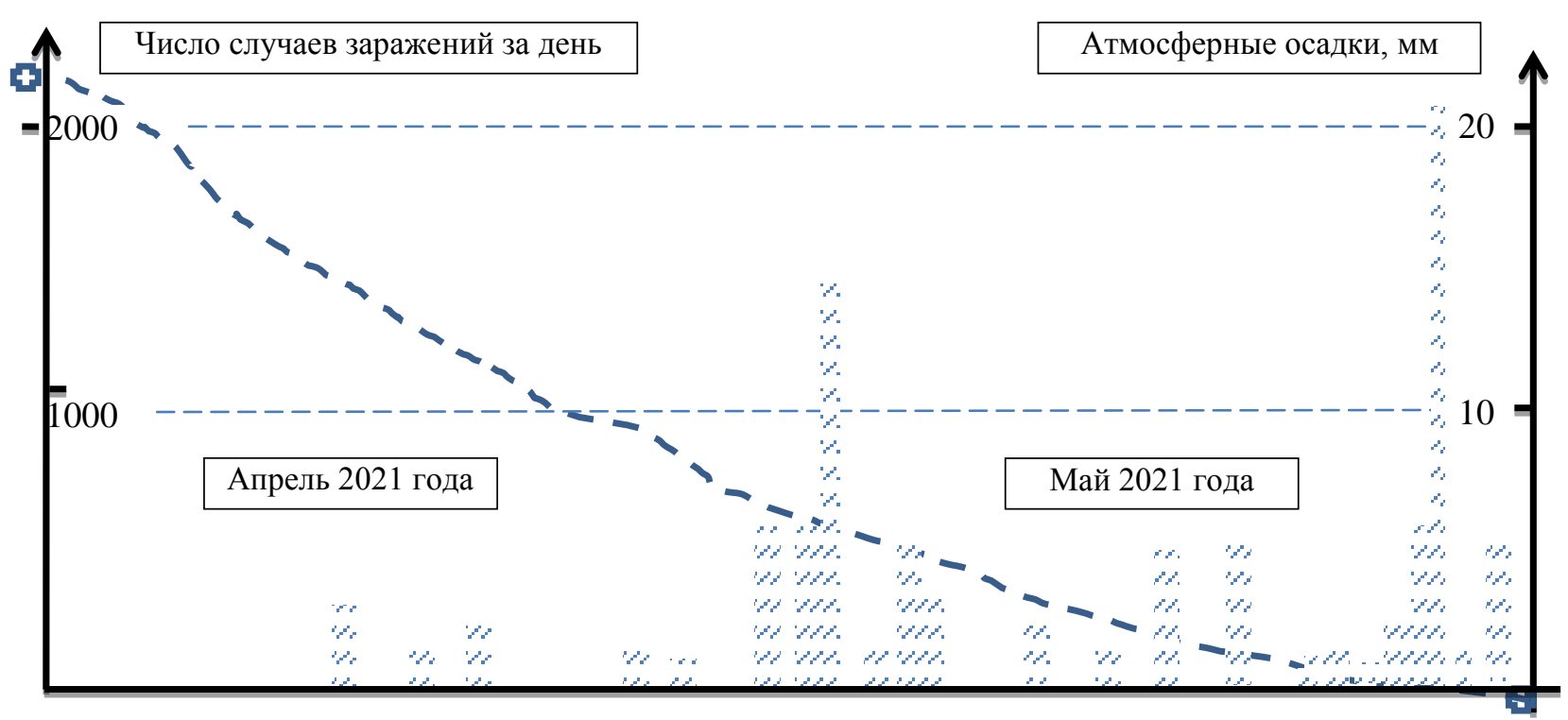

01020304050607080910111213141516171819202122232425262728293001020304050607080910111213141516171819202122232425262728293031

Рис. 1. Корреляция между уровнем заражений и интенсивностью атмосферных осадков в Республике Молдова (период апрель-май 2021 года). Выпавшие осадки - меньше среднестатистической нормы, но при этом все прошедшие дожди имели продолжительный моросящий характер, способствуя очищению воздуха от мелкодисперсных загрязнений.

ванные в июле 2021 года) результаты наблюдений ускоренного распространения коронавирусной инфекции во второй половине лета 2020 года на западе США на фоне сухой жаркой погоды и широкомасштабных лесных пожаров [59]. Соответственно жители длительное время подвергались воздействию дыма с повышенным содержанием твердых частиц (2,5 мкм в диаметре и меньше). В данном случае наличие дымовых частиц служит визуальным индикатором маршрутов воздушных потоков и повышенной загрязненности воздуха, в том числе коронавирусом. В такой ситуации атмосферные осадки способны устранить оба вида загрязнений.

В подтверждение взаимосвязи атмосферных осадков с интенсивностью распространения коронавируса на рис. 2 приведены статистические данные по Республике Индия, охватывающие сезон муссонных дождей 2021 года. (Отметим, что благодаря широкой базе статистические данные по Индии отличаются дополнительной достоверностью.) Очевидно, что в муссонный период 2021 года в Индии наблюдалось значительное (более чем на порядок) снижение уровня заражений за день, что можно объяснить последовательным избавлением атмосферного воздуха от коронавируса за счет атмосферных осадков.

Распространению коронавируса воздушным путем способствует его устойчивость как при низких температурах зимой, так и относительно высоких летом [2]. В отличие от вышеупомянутых респираторных вирусных эпидемий XXI века, COVID-19 в меньшей степени проявляет сезонную зависимость от факторов окружающей среды - летом 2020 и 2021 годов не наблюдалось ожидавшееся значительное снижение заражений. При этом следует заметить, что дневное ультрафиолетовое излучение от Солнца (главным образом в диапазонах $U V-A$ и $U V-B$, так как $U V$-C практически полностью поглощается атмосферой) малоэффективно по отношению к вирусу COVID-19.

Контроль за распространением коронавирусной инфекции $S A R S-C o V-2$ существенно затруднен положительным, на первый взгляд, фактором - многочисленным бессимптомным или слабо выраженным течением болезни, наблюдаемым примерно в $80 \%$ случаев. (В связи с этим следует заметить, что вакцинация не должна служить поводом для необоснованных послаблений, так как может усугубить данный фактор и способствовать росту процента бессимптомных и слабо выраженных случаев.) Зараженный человек, еще находящийся в инкубационном периоде заболевания и не имеющий клинических проявлений, уже может являться источником инфекции (латентный период при коронавирусной инфекции SARS-CoV-2 обычно короче инкубационного). Как следствие, в результате эпидемиологических мер под санитарным контролем (в изоляции) оказывается лишь малая часть источников заражений, и соответственно коэффициент заражения коронавирусом $R_{t}$ возрастает $\left(R_{t}>1\right)$.

На практике наблюдаются две существенно отличающиеся ситуации заражения:

1. Превентивные меры (масштабное тестирование в группах риска, адекватные карантинные 


\section{Daily New Cases in India}

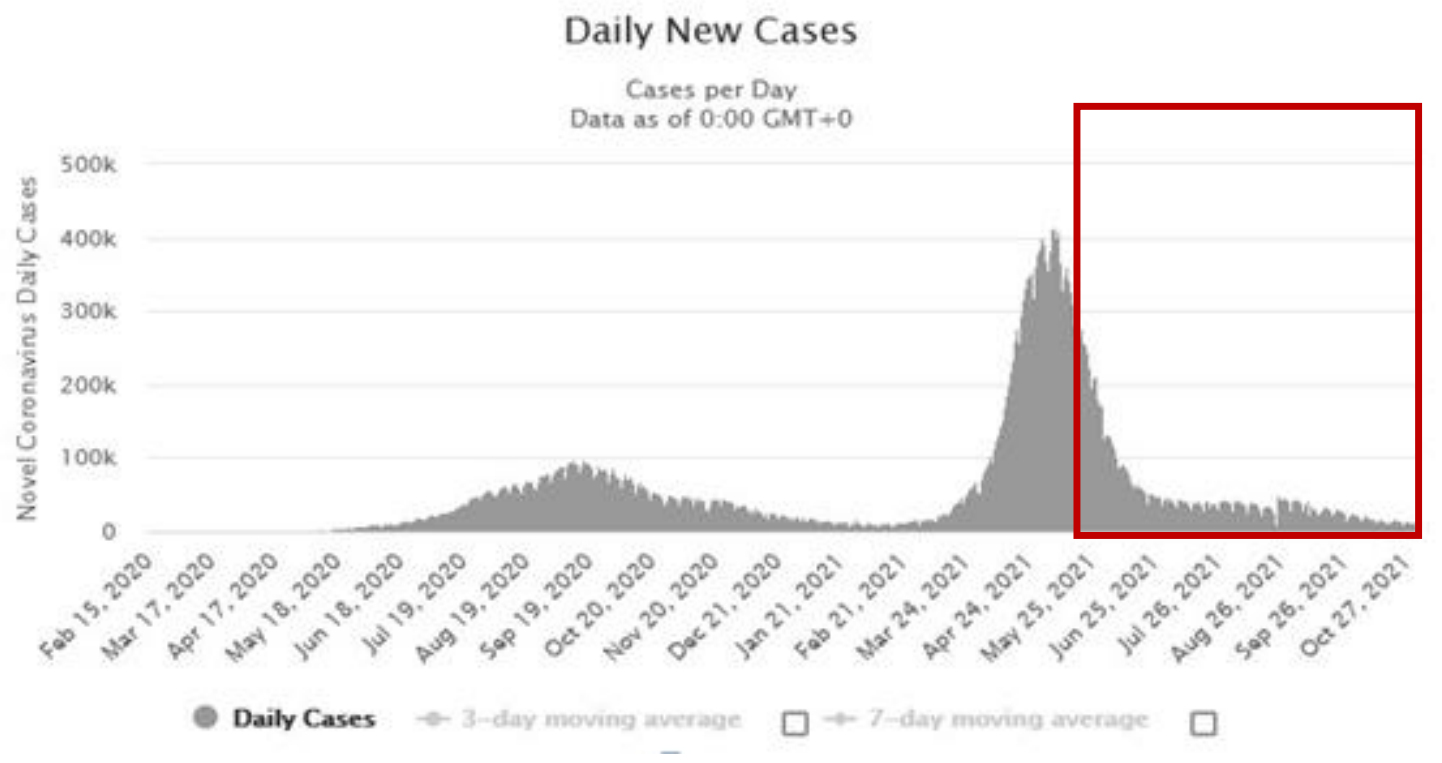

Рис. 2. Корреляция между уровнем дневных заражений и наличием атмосферных осадков в Республике Индия (официальные данные). Прямоугольником отмечен влажный и теплый период, соответствующий действию (традиционного для Индии) юго-западного муссона. Наблюдается заметное (более чем на порядок) снижение уровня дневных заражений по нашему мнению, главным образом благодаря очищению воздуха от коронавируса за счет атмосферных осадков.

меры, вакцинация и т.д.) позволяют своевременно выявлять очаги заражения на ранних стадиях, что дает возможность медикам и другим государственным структурам отслеживать отдельные заражения и ликвидировать цепочки распространения инфекции $\left(R_{t}<1\right)$.

2. Высокие уровни заражения превышают возможности контроля эпидемии со стороны медицинской системы, эпидемия разрастается $\left(R_{t}>1\right)$, затраты и потери резко возрастают.

Следовательно, необходимо стремиться сохранять контроль над распространением инфекции, действуя по п. 1 , когда $R_{t}<1$. В случае же потери контроля над разрастанием эпидемии $\left(R_{t}>1\right)$, с учетом большого числа взаимодействующих факторов заражения [3-6], на сегодняшний день единственной крайне затратной, но действенной мерой, обеспечивающей быстрое, оперативное ограничение распространения коронавирусной инфекции SARS-CoV-2, является карантин (lockdown) аргументированной жесткости. В результате властные структуры должны регулировать жесткость карантина, балансируя между причиняемым экономическим ущербом и угрозами здоровью населения (соответственно стремясь к ситуации эффективного контроля заражений, с коэффициентом распространения инфекции $\left.R_{t}<1\right)$. Для снижения числа заражений крайне важно своевременно и на адекватном уровне внедрить надежную микробиологическую деконтаминацию.
Оптимизация микробиологической деконтаминации (в особенности воздушной среды и поверхностей), с учетом неизбежной перспективы появления новых эпидемических угроз, становится сегодня приоритетной цивилизационной задачей. Парадоксально, но социальный и экономический прогресс, адресованный homo sapiens, одновременно влечет за собой и создание более благоприятных условий для сосуществования (к сожалению, не всегда безвредного) с многочисленными бактериями и вирусами.

Приходится констатировать, что в целом применяемые сегодня меры борьбы с вредоносными бактериями и вирусами остаются паллиативными. Бактерии успешно используют свой природный механизм эволюции, приспособления к действию постоянно обновляемых антибиотиков, приобретая антибиотикорезистентность. Чрезмерно широкое употребление антибиотиков неизбежно приводит к их попаданию в окружающую среду, где микроорганизмы вырабатывают и в последующем переносят генетическую информацию устойчивости к антибиотикам. Сложности в противостоянии процессу адаптации микроорганизмов к антибиотикам укрепляют мнение о неизбежном наступлении «антибиотического апокалипсиса». В свою очередь, паразитная неклеточная (и самая многочисленная) биологическая формация на Земле на грани живого - вирусы - периодически испытывает эффективность иммунной системы человека обновленными штаммами (мутациями). 
К сожалению, приобретенный иммунитет (в том числе в результате противовирусной вакцинации) имеет ограниченный срок действия - до неизбежного появления очередной, более резистентной и агрессивной мутации вируса. Мутации являются имманентным свойством вирусов. Поэтому всегда существует вероятность непредсказуемого появления вирулентной формы вируса, способной перечеркнуть масштабные, дорогостоящие и инерционные усилия по разработке и внедрению вакцин. Выявленные штаммы SARS-CoV-2 пока не оказали катастрофическое влияние на течение пандемии, но в будущем они могут помочь вирусу ускользнуть от иммунной системы, вакцин или терапии антителами [7].

Пандемия COVID-19 является первопричиной многоплановых социально-экономических потрясений, крупнейшей мировой рецессии после Великой депрессии прошлого века, что предопределяет актуальность оптимизации микробиологической деконтаминации.

\section{ОПТИМИЗАЦИЯ МИКРОБИОЛОГИЧЕСКОЙ ДЕКОНТАМИНАЦИИ}

Цель данной публикации - предложение методов и средств микробиологической деконтаминации, оптимальных по критическим параметрам (быстрая, необратимая, универсальная стерилизация; неограниченный срок годности; максимальная энергоэффективность; экологическая безопасность, простота, доступность, приемлемая стоимость и т.д.).

Микробиологическая деконтаминация (стерилизация) традиционно представлена набором классических (стандартных) физических и химических методов, включая нагревание, химикаты, облучения различными частотами, высокое давление, фильтрацию. В последнее время все большее распространение получают плазменные системы стерилизации. Однако при обилии технологий стерилизации остаются нерешенными серьезные проблемы, среди которых: отсутствие $100 \%$ гарантии качества (стерильности), высокая стоимость и сложность оборудования, вредность для персонала и экологии, длительность процесса и т.д. Особой проблемой является стерилизация воздушных масс и поверхностей, составляющая основной объект данной работы.

Живой является формация, способная к самовоспроизведению - причем с обязательными изменениями - за счет аккумулируемой из окружающей среды свободной энергии. Диапазон «живого» чрезвычайно велик - от неклеточных прионов и вирусов до сложнейшего организма человека. Существует закономерность - чем проще (меньше по размерам) живая формация, тем она менее уязвима и соответственно, трудно обнаружима и опасна (характерный пример прионы, даже не содержащие нуклеиновых кислот). С другой стороны, неклеточные формации при получении повреждений уже не имеют никаких шансов на их устранение - в отличие от клеточных организмов у них отсутствуют репаративные механизмы.

Для оптимизации процессов микробиологической стерилизации применим и результативен термодинамический («энергетический») подход. Bce процессы вблизи земной поверхности протекают при постоянном (в среднем) давлении и температуре. Поэтому именно изобарноизотермический потенциал, или свободная энергия Гиббса $G=H-T S$, характеризует полную потенциальную энергию термодинамической системы (организма, или более простой формации). Поступление свободной (то есть высокопотенциальной, высококачественной) энергии из окружающей среды является обязательным условием для поддержания жизни. При этом на Земле практически единственным значащим первичным источником свободной энергии является Солнце.

В отсутствие притока свободной энергии извне все системы неизбежно самопроизвольно стремятся к минимуму свободной энергии $G-$ за счет расхода энтальпии $H$ и роста неупорядоченности (беспорядка) $S$. Таким образом, протекание изобарно-изотермического процесса определяется двумя факторами: энтальпийным, связанным с изменением энтальпии системы $(\Delta H)$, и энтропийным $(T \Delta S)$, обусловленным изменением порядка в системе (изменением энтропии). Разность этих термодинамических факторов является функцией состояния системы.

Динамика роста (или деградации) организма при заданной температуре и давлении характеризуется изменением накопленной свободной энергии:

$$
\Delta G=\Delta H-T \Delta S .
$$

Увеличение свободной энергии в организме (за счет ассимиляции энергии из окружающей среды) является обязательным условием его существования (роста и умножения); соответственно уменьшение свободной энергии означает деградацию и, в конечном итоге, гибель живой формации (см. рис. 3). Таким образом, для достижения деконтаминации следует добиваться снижения свободной энергии живой формации (до определенного предела, когда наступает гарантированная нежизнеспособность).

Применительно к клеточным (относительно сложным) живым организмам принципиально 


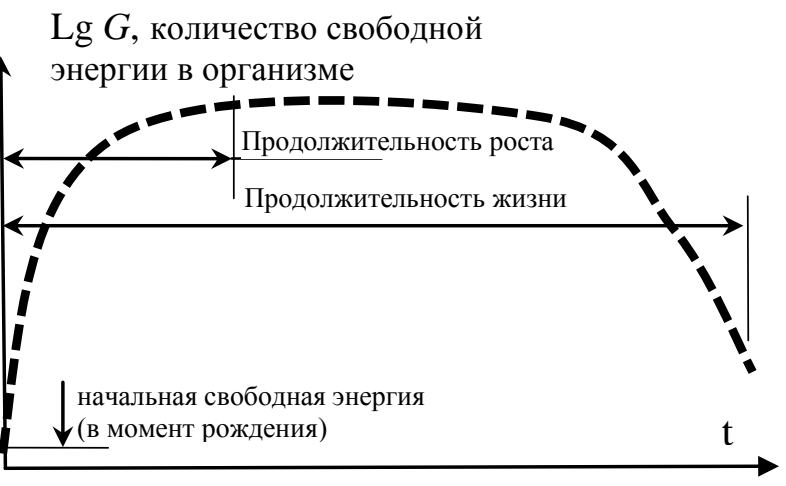

Рис. 3. Вариация свободной энергии в организме в течение жизни.

Таблица 1. Константы атомов (молекул), определяющие окислительные свойства [9-11]

\begin{tabular}{|c|c|c|c|c|c|}
\hline Молекулы & $\mathrm{F}_{2}$ & $\mathrm{Cl}_{2}$ & $\mathrm{O}_{2}$ & $\mathrm{O}_{3}$ & $\mathrm{~N}_{2}$ \\
\hline $\begin{array}{c}\text { Энергии связи } \\
\text { (диссоциации ) молекул, } \\
\text { эВ (кДж/моль) } \\
\text { и наибольшие длины } \\
\text { волн } \lambda_{\max }-\text { предел } \\
\text { диссоциации) }\end{array}$ & $\begin{array}{c}1,61(155,0) \\
\left(\lambda_{\max }=772,0 \mathrm{HM}\right) \\
\mathrm{F}_{2}+h v \rightarrow \mathrm{F}+\mathrm{F}\end{array} \mid$ & $\begin{array}{c}2,52(242,6) \\
\left(\lambda_{\max }=493,3 \mathrm{HM}\right) \\
\mathrm{Cl}_{2}+h v \rightarrow \\
\mathrm{Cl}+\mathrm{Cl}\end{array}$ & $\begin{array}{c}5,12(493,6) \\
\left(\lambda_{\max }=242,4 \text { Hм }\right) \\
\mathrm{O}_{2}+h v \rightarrow \mathrm{O}+\mathrm{O}\end{array}$ & $\begin{array}{c}1,11(107,0) \\
\left(\lambda_{\max }=1117,3 \mathrm{HM}\right) \\
\mathrm{O}_{3}+h v \rightarrow \\
\mathrm{O}_{2}+\mathrm{O}\end{array}$ & $\begin{array}{c}9,81(945,3) \\
\left(\lambda_{\max }=126,6 \mathrm{HM}\right) \\
\mathrm{N}_{2}+h v \rightarrow \mathrm{N}+\mathrm{N}\end{array}$ \\
\hline $\begin{array}{c}\text { Сродство к электрону, } \\
\text { эВ (кДж/моль) }\end{array}$ & $\begin{array}{c}3,45(332,7) \\
\text { (для атома F) }\end{array}$ & $\begin{array}{c}3,61(348,7) \\
\text { (для атома Cl) }\end{array}$ & $\begin{array}{c}1,47(141,5) \\
\text { (для атома О) } \\
0,44(42,4) \\
\left.\text { (для молек. } \mathrm{O}_{2}\right) \\
\end{array}$ & $\begin{array}{c}2,26(217,9) \\
\text { (для молекулы } \\
\left.\mathrm{O}_{3}\right)\end{array}$ & $\begin{array}{c}-0,21(-20) \\
\text { (для атома N) }\end{array}$ \\
\hline $\begin{array}{c}\text { Энергия ионизации } \\
\text { (атомов, молекул), эВ }\end{array}$ & $\begin{array}{c}17,42 \\
(\mathrm{~F}+h v \rightarrow \\
\left.\mathrm{F}^{+}+\mathrm{e}\right) \\
15,70 \\
\left(\mathrm{~F}_{2}+h v \rightarrow\right. \\
\left.\mathrm{F}_{2}^{+}+\mathrm{e}\right) \\
\end{array}$ & $\begin{array}{c}12,96 \\
(\mathrm{Cl}+h v \rightarrow \\
\left.\mathrm{Cl}^{+}+\mathrm{e}\right) \\
11,48 \\
\left(\mathrm{Cl}_{2}+h v \rightarrow\right. \\
\left.\mathrm{Cl}_{2}^{+}+\mathrm{e}\right)\end{array}$ & $\begin{array}{c}13,62 \\
(\mathrm{O}+h v \rightarrow \\
\left.\mathrm{O}^{+}+\mathrm{e}\right) \\
12,08 \\
\left(\mathrm{O}_{2}+h v \rightarrow\right. \\
\left.\mathrm{O}_{2}^{+}+\mathrm{e}\right)\end{array}$ & $\begin{array}{c}12,52 \\
\left(\mathrm{O}_{3}+h v \rightarrow\right. \\
\left.\mathrm{O}_{3}^{+}+\mathrm{e}\right)\end{array}$ & $\begin{array}{c}14,53 \\
(\mathrm{~N}+h v \rightarrow \\
\left.\mathrm{N}^{+}+\mathrm{e}\right) \\
15,58 \\
\left(\mathrm{~N}_{2}+h v \rightarrow\right. \\
\left.\mathrm{N}_{2}^{+}+\mathrm{e}\right) \\
\end{array}$ \\
\hline $\begin{array}{c}\text { Электроотрицательность } \\
\text { атомов } \\
\left(\text { по LPauling, } \text { эВ }^{-1 / 2}\right)\end{array}$ & 3,98 & 3,16 & 3,50 & 3,50 & 3,05 \\
\hline $\begin{array}{c}\text { Электроотрицательность } \\
\text { атомов (по [11], б/p) }\end{array}$ & 4,00 & 3,50 & 3,78 & 3,78 & 3,56 \\
\hline $\begin{array}{c}\text { Ковалентный радиус } \\
\text { атомов, нм }\end{array}$ & 0,064 & 0,099 & 0,066 & 0,066 & 0,074 \\
\hline
\end{tabular}

возможно использование для стерилизации феномена апоптоза - «клеточного суицида» неугодных клеток. Перспективы применения знаний о программируемой клеточной смерти связаны не только с возможностями деконтаминации, но также и с лечением онкологических, аутоиммунных и других заболеваний. В настоящее время устанавливаются механизмы реализации апоптоза, активно ведутся исследования его регуляторов и активаторов. Как следует из дальнейшего анализа, оптимальным индуктором апоптоза должны быть активные формы кислорода. В работе [8] этот факт подтверждается экспериментально перекись водорода $\left(\mathrm{H}_{2} \mathrm{O}_{2}\right)$ является эффективным триггером апоптоза. Однако по сей день остается нерешенной проблема избирательного воздействия на целевые клетки.

К сожалению, по отношению к неклеточным структурам (вирусам, прионам) механизм программируемого апоптоза неприменим соответственно, следует искать другие решения. Покажем, что надежный и кратчайший путь к достижению стерилизации - обеспечение необратимых химических реакций окисления агентов заражения.

Для реализации поддерживающих жизнь обратимых неспонтанных (эндотермических) реакций изменение свободной энергии обязательно должно быть положительным $(\Delta G>0)$, что означает потребность во внешнем подводе энергии. Показательным примером неспонтанной эндотермической реакции, символизирующей жизнь, является реакция фотосинтеза, для которой поглощение высокопотенциальной солнечной энергии является обязательным условием реализации:

$$
6 \mathrm{CO}_{2}+6 \mathrm{H}_{2} \mathrm{O} \stackrel{h v}{\longrightarrow} \mathrm{C}_{6} \mathrm{H}_{12} \mathrm{O}_{6}+6 \mathrm{O}_{2} \text {. }
$$


Обратная реакция (3) - окисления - напротив, является самопроизвольной экзотермической реакцией и означает разрушение органической жизни. Высвобождение низкопотенциальной энергии $Q$ («мертвой» энергии) делает эту реакцию необратимой (соответственно для нее $\Delta G<0)$ :

$$
\mathrm{C}_{6} \mathrm{H}_{12} \mathrm{O}_{6}+6 \mathrm{O}_{2} \rightarrow 6 \mathrm{CO}_{2}+6 \mathrm{H}_{2} \mathrm{O}+\mathrm{Q} \text {. }
$$

В таких спонтанных экзотермических реакциях окисления полное уменьшение свободной энергии $(\Delta G<0)$ происходит из-за увеличения энтропии (степени беспорядка) $\Delta S$ и уменьшения энтальпии (теплосодержания) $\Delta H \quad$ см. формулу (1).

Таким образом, необратимые химические реакичи окисления являются кратчайшим способом достижения стерильности. Они способны обеспечить стопрочентную надежность деконтаминации - при условии достаточного снижения («сжчгания») свободной энергии, содержашейся в вирулентных формах, путем окисления и преобразования в конечном итоге органических соединений в газовую фазу.

Выбрать наилучший окислитель можно, используя данные табл. 1, которые показывают, что атом фтора - самый сильный из имеющихся в природе окислителей (фтор способен окислить даже кислород с образованием дифторида кислорода $\left.\mathrm{OF}_{2}\right)$. Однако фтор настолько активен, что любые манипуляции с ним чрезвычайно опасны (по отношению к фтору стабильны только алмаз и некоторые виды стеклоуглерода). Кроме того, масштабное внедрение фтора в качестве окислителя нарушило бы существующее природное равновесие.

Поэтому атомарный кислород - второй по окислительной активности элемент (см. табл. 1) -наиболее приемлемый (оптимальный) окислитель. Выбор кислорода в качестве оптимального окислителя логичен и естественен - кислород является самым распространенным (по массе) элементом земной коры. Живые организмы примерно на 70\% по массе состоят из кислорода, a также получают энергию для поддержания жизни за счет биологического окисления вдыхаемым кислородом органических накоплений. Таким образом, кислород экологически идеален в качестве окислителя, он гармонично вписывается в естественные ичиклы обмена.

К сожалению, из конъюнктурных соображений во многих случаях в качестве основного стерилизующего средства был выбран - и до сих пор им остается - хлор, или его производные.

Следует, однако, отметить, что использование хлора в водоподготовке - вынужденная мера, применяемая в особенности для водопроводных сетей большой протяженности (характерных для мегаполисов). Окислительные свойства кислорода выше, чем у хлора (см. табл. 1), но атомарный кислород и образуемый им озон - продукты «скоропортящиеся» (озон самопроизвольно распадается в воздухе и воде за несколько десятков минут). Хлор менее активен, не склонен к самораспаду и соответственно сохраняет значительное последействие, гарантируя определенную долговременную микробиологическую безопасность. Однако при использовании антропогенного хлора в водоподготовке платой за безопасность становятся другие угрозы здоровью потребителей - при хлорировании могут образовываться значительные количества хлорорганических соединений, многие из которых токсичны, как, например, диоксины. Длительное воздействие диоксинов приводит к поражениям иммунной системы, формирующейся нервной системы, эндокринной системы, а также репродуктивных функций.

Поэтому следует минимизировать употребление хлора в водоподготовке, заменяя его озоном. Безусловно, целесообразно использование озона при водоподготовке в малогабаритных автономных системах. Применительно к протяженным системам водообеспечения, вынужденно использующим хлорирование, целесообразно в nuщзевых цุелях употреблять озонированную воду из альтернативных источников (озонированная вода практически не содержит токсинов), либо использовать фильтрацию через слой высококачественного адсорбента. Важно отметить, что кипячение хлорированной воды лишь стимулирует образование ядовитых хлорорганических соединений. Перспектива устойчивого развития связана с полным исключением хлора из процесса микробиологической деконтаминации - за счет совершенствования окисления озонированием (что является оптимальным решением, так как соответствует достижению результата при минимальном расходе свободной энергии $\Delta G)$.

Применительно к микробиологической деконтаминации воздушной среды и поверхностей - оптимальным средством стерилизации является неравновесная («холодная») кислородная плазма, создающая реакционноактивные формы кислорода. Этот вывод следует из того, что большинство традиционных физических и химических методов деконтаминации (тепловая стерилизация, химикаты, высокое давление, ультразвук, фильтрация) обладают ограниченной надежностью при высоких затратах, «работают» в ограниченном объеме и малоэффективны по отношению к пространственно-распределенным объектам. 
Исключение составляют различные виды электромагнитного излучения - ультрафиолетовый свет, рентгеновские лучи и гамма-лучи, a также облучения субатомными частицами (например, электронными пучками). Данные высокоэнергетические ионизирующие воздействия вызывают «эндотермические» структурные разрушения (при которых $\Delta G>0$ ), ведут к образованию свободных радикалов, в том числе ионизированных. При этом радиационное разложение молекул кислорода и воды означает генерацию сильных окислителей - соответственно атомарного кислорода и гидроксильного радикала $(\mathrm{O}$ и $\mathrm{OH})$, способствующих дезактивации объекта. Однако, параллельно возможны процессы репараций и образования мутаций жизнеспособных (вирулентных) форм. (Заметим, что при микробиологической деконтаминации неравновесной кислородной плазмой мутагенез принципиально невозможен.) Отмеченные особенности физических методов стерилизации (рентгеновских и гамма-лучей, облучений ускоренными частицами), наряду с их дороговизной и сложностью обеспечения безопасности, являются труднопреодолимыми препятствиями для их использования в целях деконтаминации воздуха и поверхностей.

Ультрафиолетовый спектр электромагнитного излучения заслуживает дополнительного рассмотрения - ввиду его относительно большей безопасности, доступности и распространенности. Искусственными генераторами ультрафиолета промышленного и бытового применения - преимущественно на базе газоразрядных ламп - обеспечены ближний ( $U V-A$, $\lambda=315-400$ нм, $E_{h v}=3,10-3,94$ эВ), средний $\left(U V-B, \lambda=280-315 \mathrm{нм}, E_{h v}=3,94-4,43\right.$ эВ $)$ и дальний ультрафиолет ( $U V-C, \lambda=100-280 \mathrm{HM}$, $E_{h v}=4,43-12,4$ эВ). Энергии ультрафиолетовых квантов в диапазоне $U V$ - $C$ достаточно для фотодиссоциации биологических молекул (в частности ДНК, РНК и белков), но недостаточно для практически значимых ионизаций. Заметим, что существенной ионизирующей способностью обладает экстремальный ультрафиолет $(E-U V, \quad \lambda=10-121 \mathrm{HM}$, $E_{h v}=10,25-124$ эВ), однако он не востребован, в том числе из-за сложности и дороговизны генерации (на сегодняшний день - обычно лазерной). Диапазон $U V$ - $C$ обладает важным достоинством в плане обеспечения деконтаминации - энергии его квантов достаточно для фотодиссоциации молекул кислорода $\left(\mathrm{O}_{2}\right)$ и воды $\left(\mathrm{H}_{2} \mathrm{O}\right)$, с образованием окислительных радикалов - атомарного кислорода $(\mathrm{O})$ и гидроксила $(\mathrm{OH})$ :

$$
\begin{gathered}
\mathrm{O}_{2}+h v \rightarrow \mathrm{O}+\mathrm{O}(\Delta H=493,6 \text { кДж/моль }) ; \\
\mathrm{H}_{2} \mathrm{O}+h v \rightarrow \mathrm{H}+\mathrm{OH}(\Delta H=498,7 \text { кДж/моль }) .(4)
\end{gathered}
$$

Окисляющие радикалы (О и $\mathrm{OH})$ образуются как в воздухе, так и во влажных поверхностных слоях (глубина проникновения фотонов $U V-C-$ несколько микрометров), способствуя необратимости обеззараживания и препятствуя мутациям. Таким образом, присутствие кислорода и влаги необходимое условие для достижения эффективной деконтаминации ультрафиолетом $U V-C$. Показательно, что в безводной и бескислородной среде снижается стерилизующая способность ультрафиолета любой жесткости. В 2020 году японские исследователи экспериментально доказали, что гранулы высушенных бактерий, прилипшие к внешней стороне станции (МКС), могут выжить в космосе более трех лет [12]. Несомненно, что под действием жесткого космического ультрафиолета происходила неоднократная фотодиссоциация компонентов сухих бактерий, однако отсутствие окислителей в условиях космического вакуума приводило к восстановлению (рекомбинации) нарушенных связей.

Солнечное излучение в диапазоне $U V$ - $C$ практически полностью поглощается атмосферой (преимущественно в озоновом слое), поэтому не следует рассчитывать на существенное дневное солнечное обеззараживание благодаря естественному ультрафиолету. Бездействие в затененных местах - немаловажный имманентный недостаток ультрафиолетового излучения, который устраняется при стерилизации диффундирующими окислительными агентами, генерируемыми в газовой плазме.

Обобщая изложенное, следует отметить, что самостоятельное использование ультрафиолета не является оптимальным и надежным вариантом деконтаминачии воздушной среды и поверхностей, хотя и приносит пользу благодаря снижению дозы инфицирования (вирусной нагрузки). При этом эрозия микроорганизмов благодаря фотодиссоциации ультрафиолетом существенно менее эффективный механизм, чем непосредственное травление (окисление поверхностных слоев) активными формами кислорода.

НЕРАВНОВЕСНАЯ («ХОЛОДНАЯ»)

КИСЛОРОДНАЯ ПЛАЗМА, ГЕНЕРИРУЮЩАЯ

РЕАКЦИОННО-АКТИВНЫЕ ФОРМЫ

КИСЛОРОДА, - ОПТИМАЛЬНОЕ СРЕДСТВО МИКРОБИОЛОГИЧЕСКОЙ

ДЕКОНТАМИНАЦИИ ВОЗДУШНОЙ СРЕДЫ И ПОВЕРХНОСТЕЙ

Источником реакционно-активных форм кислорода может служить четвертое агрегатное состояние вещества - плазма, генерируемая в газовых разрядах. Спектр применений газообразной плазмы, генерируемой электро- 
физическими методами, непрерывно расширяется - от аэрокосмических технологий до медицины и пищевой промышленности [13-53]. Особый интерес представляет низкотемпературная (неравновесная, «холодная» плазма) при атмосферном давлении - ввиду ее энергоэкономичности и относительной простоты широкого внедрения.

Газовая плазма - высокоэнергетическое квазинейтральное состояние газа (с определенной долей ионизации компонентов, а также диссоциации молекул с образованием радикалов высокой химической активности). Для создания и поддержания неустойчивого (неравновесного) плазменного состояния газа необходим непрерывный подвод свободной (высокопотенциальной) энергии извне $(\Delta G>0)-$ в этом условие существования плазмы совпадает с условием существования жизни. Соответственно, энергетический баланс поддерживается непрерывным релаксационным (рекомбинационным) излучением плазмы, которое является основным проявлением для определения свойств плазмы, ионизационного баланса, температуры, плотности и содержания элементов. В отсутствие притока высокопотенциальной энергии время «гашения» плазмы при атмосферном давлении оценивается долями секунды. Таким образом, плазма является «скоропортящимся» продуктом и должна генерироваться для применений in situ.

Для целей микробиологической деконтаминации пригодна лишь низкотемпературная («холодная») кислородная плазма - по соображениям энергоэффективности при генерации, а также потребности обеззараживания термолабильных поверхностей. Такая плазма существенно неравновесна - в ней средняя кинетическая энергия электронов значительно больше таковой у молекул и ионов газа (соответственно $\left.T_{e}>T_{g}\right)$. Добиться неравновесности плазмы невозможно термическим способом - кинетическая энергия эффективно передается лишь массивным молекулам, а затем уже электронам. Задача избирательного сообщения кинетической энергии электронам решается с помощью переменного электрического поля. A priori ясно, что для генерации неравновесной плазмы следует воздействовать на газ переменным электрическим полем максимальной частоты и напряженности (естественно, превышая напряженность пробоя). При этом в тысячи раз более массивные положительные ионы практически остаются на месте и не приобретают кинетическую энергию, а легкие электроны (с таким же по величине, но отрицательным зарядом) набирают кинетическую энергию, достаточную для ионизаций. Время развития электронной лавины в газовых разрядах составляет $10^{-7}-10^{-3}$ сек [54]. Поэтому частота СВЧ-поля $f \sim 2,45$ ГГц, используемая для промышленных применений, является оптимальной по ряду признаков (доступность источников генерации, относительная простота реализации пробоя и значимой неравновесности плазмы, предотвращение контрактации разряда).

В газовом разряде (при превышении порога ионизации) происходит столкновительная ионизация электронными ударами с образованием молекулярных ионов и умножением электронов:

$$
\mathrm{O}_{2}+\mathrm{e}^{-} \rightarrow \mathrm{O}_{2}^{+}+2 \mathrm{e}^{-} ; \mathrm{N}_{2}+\mathrm{e}^{-} \rightarrow \mathrm{N}_{2}^{+}+2 \mathrm{e}^{-} .
$$

Динамический ионизационный баланс поддерживается электронной объемной рекомбинацией, которая при низкой температуре происходит главным образом диссоциативным путем:

$$
\mathrm{O}_{2}^{+}+\mathrm{e}^{-} \rightarrow \mathrm{O}+\mathrm{O} ; \mathrm{N}_{2}^{+}+\mathrm{e}^{-} \rightarrow \mathrm{N}+\mathrm{N} \text {. }
$$

Рекомбинация электронов с молекулярными ионами происходит преимущественно диссоциативно, так как в этом случае не требуется участие третьей частицы.

Также действует механизм диссоциативного прилипания электронов к молекулам кислорода, для которого существует энергетический порог 4 эВ (данная оценка следует из данных, приведенных в табл. 1):

$$
\mathrm{O}_{2}+\mathrm{e}^{-} \rightarrow \mathrm{O}^{-}+\mathrm{O}
$$

Однако на данный механизм приходится лишь относительно малый процент диссоциаций (менее 15\%).

Фактор преимущественно диссоциативной рекомбинации имеет решающее значение для получения стерилизационных качеств плазмы - в результате генерируется атомарный кислород (O), являющийся высокоактивным окислителем. Обратные реакции ассоциации (восстановления молекул $\mathrm{O}_{2}$ и $\mathrm{N}_{2}$ ) возможны, но их протекание - в нежелательном - обратном направлении затруднено необходимостью контакта с третьей частицей, поглощающей энергию ассоциации:

$$
\mathrm{O}+\mathrm{O}+M \rightarrow \mathrm{O}_{2}+M^{*} ; \mathrm{N}+\mathrm{N}+M \rightarrow \mathrm{N}_{2}+M^{*} \text {. }
$$

В качестве третьей частицы может выступать любая молекула или атом газовой смеси (включая молекулярный кислород $\mathrm{O}_{2}$ и азот $\mathrm{N}_{2}$ ).

Генерируемый в результате реакций $(6,7)$ высокоактивный и, как следствие, короткоживущий атомарный кислород $(\mathrm{O})$ представляет наибольший интерес для реализации обеззараживания. Он вступает в трехчастичную реакцию с молекулярным кислородом, образуя озон $\mathrm{O}_{3}$ : 


$$
\mathrm{O}+\mathrm{O}_{2}+M \rightarrow \mathrm{O}_{3}+M^{*} .
$$

Реакция проходит с обязательным участием третьей частицы, воспринимающей - относительно малую - энергию связи атома кислорода в молекуле озона (табл. 1: $E=1,11$ эВ, или 107,0 кДж/моль). Столь малая энергия связи предопределяет сравнительную неустойчивость молекулы озона, возрастающую с ростом температуры. С другой стороны, эта низкая энергия отрыва атома $\mathrm{O}$ от молекулы $\mathrm{O}_{3}$, вкупе с высоким сродством к электрону для $\mathrm{O}_{3}$ (табл. 1: $E=2,26$ эВ, или 217,9 кДж/моль), обусловливает высокую окислительную способность озона, необходимую для деконтаминации. Время жизни озона в благоприятных для него условиях измеряется десятками часов [55] - благодаря этому снижение его концентрации ночью в защитном озоновом слое в стратосфере несущественно, что и обеспечивает условия для жизни на Земле (путем поглощения озоном вредоносной дневной солнечной ультрафиолетовой радиации в диапазоне $\lambda=200-310$ нм). Следует рассматривать достаточную устойчивость газообразного озона как бесценный дар природы, гарантирующий органическую жизнь, а также позволяющий аккумулировать и доставлять необходимую для деконтаминации химическую энергию окисления в нужное место. (Однако, к сожалению, вопрос долговременного безопасного хранения (накопления) высококонцентрированного озона не поддается решению даже для случая жидкого или твердого (криогенного) состояния озона из-за опасности самопроизвольного лавинообразного тепловыброса - по реакции $2 \mathrm{O}_{3} \rightarrow 3 \mathrm{O}_{2}$, с взрывообразным выделением $\Delta H=$ $=-285$ кДж/моль).

Оптимальный состав плазмообразующего газа должен содержать молекулярный кислород, диссоциация которого в разряде обеспечивает в конечном итоге максимальное окисление микробиологических форм.

В уравнениях (5-6) фигурирует также молекулярный азот $\left(\mathrm{N}_{2}\right)$, что предполагает использование воздуха в качестве наиболее удобного (дешевого) плазмообразующего агента. Образующийся по уравнению (6) высокоактивный атомарный азот $\mathrm{N}$ вступает в реакции образования оксидов азота $\mathrm{NO}_{\mathrm{x}}$ (главным образом монооксида $\mathrm{NO}$ и диоксида $\mathrm{NO}_{2}$ ). Оба оксида азота - прямо и косвенно - способствуют снижению наработки озона в разряде:

$$
\mathrm{O}_{3}+\mathrm{NO} \rightarrow \mathrm{O}_{2}+\mathrm{NO}_{2} ; \mathrm{O}+\mathrm{NO}_{2} \rightarrow \mathrm{O}_{2}+\mathrm{NO} .
$$

Возможны и другие реакции нарушения озонообразования в разрядной плазме с участием оксидов азота, например:

$$
\begin{gathered}
\mathrm{NO}_{2}+\mathrm{O}_{3} \rightarrow \mathrm{NO}_{3}+\mathrm{O}_{2} \\
\mathrm{O}+\mathrm{NO}_{3} \rightarrow \mathrm{O}_{2}+\mathrm{NO}_{2} .
\end{gathered}
$$

По сумме негативных эффектов от присутствия азота в плазмообразующем газе следует вывод: азот необходимо исключить из газовой смеси, несмотря на удорожание процесса из-за необходимости предварительной сепарации кислорода. (При этом следует отметить положительную динамику совершенствования и широкого внедрения доступных концентраторов кислорода из атмосферного воздуха вплоть до бытового уровня внедрения, обеспечивающих приемлемую концентрацию кислорода до 95\%.)

Заметим, что даже в отсутствие снижающего озонообразование азота, одновременно с целевой реакцией синтеза озона (9), в плазме идет нежелательная реакция $\mathrm{O}+\mathrm{O}+M \rightarrow \mathrm{O}_{2}+M$ с обязательным участием третьей частицы $M$, поглощающей существенную энергию ассоциации (табл. 1: 5,12 эВ, или 493,6 кДж/моль) и превращающей ее в бесполезное тепло. Однако, к счастью, при имеющей место высокой концентрации молекулярного кислорода в плазме атомарный кислород со значительно большей вероятностью образует озон, нежели рекомбинирует, и энергоэффективность процесса остается высокой.

Рассмотрим вариант увлажнения (насыщения) парами воды подаваемого в плазмотрон кислорода с целью получения на выходе, наряду с озоном, перекиси водорода $\left(\mathrm{H}_{2} \mathrm{O}_{2}\right)$. В результате ударной ионизации электронами (энергия ионизации молекулы $\mathrm{H}_{2} \mathrm{O}-12,61$ эВ, или 1217,1 кДж/моль в соответствии с [10]) возникают молекулярные ионы воды:

$$
\mathrm{H}_{2} \mathrm{O}+\mathrm{e}^{-} \rightarrow \mathrm{H}_{2} \mathrm{O}^{+}+2 \mathrm{e}^{-} .
$$

Конкурирующий процесс рекомбинации электронов с ионами воды происходит большей частью путем их диссоциации, так как вероятность столкновения с подходящим третьим телом именно в процессе рекомбинации невелика:

$$
\mathrm{H}_{2} \mathrm{O}^{+}+\mathrm{e}^{-} \rightarrow \mathrm{H}+\mathrm{OH}
$$

Затрачиваемая на диссоциацию энергия $(\Delta H=498,7$ кДж/моль в соответствии с [10]) близка к таковой для иона кислорода $\mathrm{O}_{2}^{+}$ $(\Delta H=493,6$ кДж/моль соответственно табл. 1); остальная - кинетическая энергия - уносится образовавшимися в результате диссоциации радикалами.

Реакционно-высокоактивные радикалы $\mathrm{OH}$ вступают в трехчастичную реакцию, образуя перекись водорода $\left(\mathrm{H}_{2} \mathrm{O}_{2}\right)$ : 


$$
\mathrm{OH}+\mathrm{OH}+M \rightarrow \mathrm{H}_{2} \mathrm{O}_{2}+M^{*} .
$$

Уносимая частицей $M$ кинетическая энергия ассоциации $(\Delta H=214,2$ кДж/моль [10]) существенно превышает таковую в случае генерации озона $(\Delta H=107,1$ кДж/моль в соответствии с табл. 1), что свидетельствует о бо́льших потерях на бесполезный нагрев газа. Более прочная по сравнению с молекулой озона $\mathrm{O}_{3}$ молекула перекиси водорода $\mathrm{H}_{2} \mathrm{O}_{2}$ сложнее вступает в реакции окисления, требуя бо́льшую энергию активации. Соответственно результаты, приведенные в работах [56-58], свидетельствуют о лучшей результативности применения озона для обеззараживания воздуха и поверхностей по сравнению с перекисью водорода. Тем не менее у перекиси водорода существуют свои сферы приоритетного применения - это прежде всего профилактика деконтаминации поверхностей. При этом эффективность газовых дезинфицирующих средств зависит от концентрации инфекции (степени загрязнения поверхностей). Их предварительная очистка перед газовой дезинфекцией перекисью водорода (соответствующим водным раствором) для снижения вирусной нагрузки - оптимальный экологически чистый вариант: остатки перекиси водорода $\mathrm{H}_{2} \mathrm{O}_{2}$, как и озона $\mathrm{O}_{3},-$ в отличие от прочих химических реагентов - не оставляют никаких следов, кроме воды $\mathrm{H}_{2} \mathrm{O}$, кислорода $\mathrm{O}_{2}$ и тепловыделений, в соответствии с реакциями:

$$
\begin{gathered}
2 \mathrm{O}_{3} \rightarrow 3 \mathrm{O}_{2}(\Delta H=-285 \text { кДж/моль }) ; \\
2 \mathrm{H}_{2} \mathrm{O}_{2} \rightarrow 2 \mathrm{H}_{2} \mathrm{O}+\mathrm{O}_{2}(\Delta H=-196 \text { кДж/моль }) .
\end{gathered}
$$

Важным достоинством перекиси водорода является возможность ее относительно простого (по сравнению с озоном) накопления и длительного хранения - благодаря бо́льшей устойчивости молекулы $\mathrm{H}_{2} \mathrm{O}_{2}$. Для производства перекиси водорода оптимальны и в настоящее время широко используются иные методы, нежели плазма газового разряда.

Из приведенных данных следует вывод: неравновесная («холодная») плазма, генерирующая озон в чистом кислороде, - оптимальное энергосберегающее средство микробиологической деконтаминации воздушной среды и протяженных поверхностей. При массивном загрязнении поверхностей целесообразно дополнительно к обеззараживающему воздействию озона $\left(\mathrm{O}_{3}\right)$ - применение водных растворов перекиси водорода $\left(\mathrm{H}_{2} \mathrm{O}_{2}\right)$.

\section{ОБ ОПТИМАЛЬНЫХ СПОСОБАХ И УСТРОЙСТВАХ ДЛЯ ГЕНЕРАЦИИ И ПРИМЕНЕНИЯ НЕРАВНОВЕСНОЙ КИСЛОРОДНОЙ ПЛАЗМЫ}

Плазменное состояние характеризуется тем, что значительная часть молекул (атомов) газа ионизирована. Как следует из табл. 1, энергии ионизации молекул (атомов) существенно превышают энергии их диссоциации. Следовательно, в результате диссоциативной рекомбинации в плазме молекулярных газов обязательно присутствуют химически активные радикалы (нейтральные, возбужденные и ионизированные), необходимые для деконтаминации. Средняя длина свободного пробега электронов в воздухе при атмосферном давлении составляет доли микрометра. Минимальная энергия, необходимая для диссоциации целевой молекулы кислорода $\left(\mathrm{O}_{2}\right)$, составляет 5,12 эВ, а для ее ионизации - 12,08 эВ (табл. 1). Отсюда следует, что минимальная напряженность электрического поля $E$, необходимая для генерации плазмы в воздухе при атмосферном давлении, составляет единицы киловольт на сантиметр $(E \sim n \times$ кВ/см), то есть необходимо реализовать высоковольтный разряд. Однако при попытке создания высоковольтного разряда при атмосферном давлении значительной длительности (сравнимой со временем развития электронной лавины в газовых разрядах) между плоскими проводящими электродами неизбежно приходится сталкиваться с контрактацией разряда, то есть с быстрым его переходом в искровой, а затем и в разрушительный дуговой разряд. Преодоление контрактации возможно с помощью коронного разряда (в котором ток ограничивается малой площадью коронирующих электродов), барьерного разряда (в котором стабилизация достигается установкой на электроды диэлектриков, с подачей на них переменного напряжения), а также благодаря использованию достаточно коротких импульсов (наносекундных, с $T \sim 10^{-9}$ сек, как следует из предыдущего изложения). Перечисленные виды разрядов целесообразно использовать как самостоятельные генераторы озона относительно малой производительности (из-за их низкой энергоэффективности и дороговизны).

Оптимальным, на наш взгляд, решением задачи генерации озона является применение безэлектродного микроволнового (сверхвысокочастотного - СВЧ) разряда [60]. Отсутствие электродов означает не только удобство в исполнении аппликатора, но и исключение тепловых потерь на электродах, а также возможного их распыления. В сверхвысокочастотном разряде коэффициент преобразования электрической энергии в плазменное состояние достигает больших величин (свыше 80\%), недостижимых для других видов разряда. Это происходит благодаря тому, что в тысячи раз более массивные положительные ионы практически не успевают набрать значимую кинетическую энергию 
за короткий полупериод колебаний (менее $T \sim 10^{-9}$ сек), и вся кинетическая энергия достается несравненно более легким электронам. Быстрые, но легкие электроны плохо передают энергию массивным частицам, что и приводит к существенной неравновесности микроволновой плазмы с $T_{e}>>T_{g}$. Риск контрактации снижается благодаря объемному характеру СВЧ-разряда и короткому периоду колебаний (T $\sim 10^{-9}$ сек мал в сравнении с временем развития электронной лавины: 10 $0^{-7}-10^{-3}$ сек). Максимальная плотность и, соответственно, реакционная способность СВЧ-плазмы также недоступны для иных видов разряда. Относительно высокая плотность плазмы СВЧ-разряда (соответственно повышенная концентрация свободных электронов) обеспечивает эффективное поглощение микроволновой энергии [61]. Перечисленные достоинства неравновесной микроволновой плазмы особо важны при деконтаминации больших объемов воздуха и протяженных поверхностей.

Наибольшая реакционная способность наблюдается непосредственно в факеле СВЧплазмы и зависит в том числе от состава рабочей смеси. Естественно, что по мере удаления от факела концентрация реакционноактивных частиц резко снижается. Поэтому реакционный потенциал микроволновой плазмы удается в полной мере реализовать лишь применительно к относительно малым, непосредственно контактирующим с плазмой поверхностям.

Выбор состава рабочей смеси определяется целями, которые ставятся при плазменном воздействии. Например, присутствие моноатомного гелия (Не) в плазмообразующем газе позволяет рассчитывать на генерацию ультрафиолета наибольшей жесткости (так как энергия первой ионизации инертного атома Не наибольшая из всех атомов - составляет 24,59 эВ [10]). Плазма чистого кислорода состоит из нейтральных молекул $\mathrm{O}_{2}$, а также атомарного кислорода $\mathrm{O}$, озона $\mathrm{O}_{3}$, супероксида $\mathrm{O}_{2}^{-}$и электронов. Положительные ионы (главным образом $\left.\mathrm{O}_{2}^{+}\right)$быстро рекомбинируют путем диссоциации. Кроме того, перечисленные молекулы, атомы и ионы могут находиться в возбужденном состоянии. СВЧ-плазма служит продуктивным источником атомарных частиц (в данном случае - атомарного кислорода О), причем их выход зависит от присутствия других молекул. Наличие водяных паров $\left(\mathrm{H}_{2} \mathrm{O}\right)$ в кислороде обеспечивает генерацию всех окислительных реакционно-активных форм кислорода атомарного кислорода $(\mathrm{O})$, озона $\left(\mathrm{O}_{3}\right)$, гидроксильного радикала $(\cdot \mathrm{OH})$, перекиси водорода
$\left(\mathrm{H}_{2} \mathrm{O}_{2}\right)$, супероксида (иона молекулы кислорода с неспаренным электроном $\mathrm{O}_{2}^{-}$), синглетного кислорода - возбужденного состояния кислорода $\mathrm{O}_{2}\left(a^{1} \Delta_{g}\right)$, с периодом полураспада при нормальных условиях 72 минуты). За счет генерации перечисленных реакционно-активных форм кислорода неравновесная («холодная») плазма является оптимальным средством локальной микробиологической деконтаминации. Заметим, что не существует информации о том, что какие-либо микроорганизмы могут противостоять уничтожающему воздействию окислительной низкотемпературной плазмы.

Справедливости ради следует заметить, что «патент» на использование оптимальных реакционно-активных форм кислорода принадлежит природе: в подтверждение этого в работе [62] показано, что в человеческом организме при необходимости синтезируются даже такие сильные окислители, как озон $\left(\mathrm{O}_{3}\right)$ и трехокись водорода $\left(\mathrm{H}_{2} \mathrm{O}_{3}\right)$ - из синглетного кислорода и воды.

Для реализации деконтаминации значительных объемов воздуха и протяженных удаленных поверхностей оптимальным, на наш взгляд, является использование озона, генерируемого in situ в микроволновой (СВЧ) кислородной плазме. Дополнительным аргументом такого решения служит широкая, близкая к повсеместной распространенность технологии микроволнового нагрева в быту и на производстве, причем с использованием генераторов достаточной мощности (в целом в мире произведены и находятся в эксплуатации многие миллионы СВЧ-печей резонаторного типа). Для придания дополнительной опции (функции) - плазменного генератора реакционно-активных форм кислорода, включая озон, - требуется лишь относительно простая доработка с сохранением базового назначения микроволновой печи. Предпочтительно, но не обязательно использовать микроволновую печь с диссектором, обеспечивающим лучшую равномерность распределения СВЧ-поля по объему, а также с варьируемой частотой (variable frequency microwave oven). Это желательно, так как в резонаторах (даже в многомодовых) электромагнитное поле стоячих волн неоднородно соседние узлы и пучности располагаются на расстоянии четверти длины волны $\Lambda$.

Для исключения образования в плазме токсичных оксидов азота $\left(N O_{X}\right)$ желательно максимально очистить воздух от азота или использовать медицинский кислород.

Инициирование СВЧ-разряда в аппликаторе микроволновой печи возможно с помощью 
различного вида игнайтеров - пламени различного происхождения (пламени бытового газа, газовой зажигалки, спиртовки и т.п.), вспомогательных электрических разрядов (например, коронного), а также пассивных металлических антенн-концентраторов электрического поля специальной конструкции. После розжига такой разряд может функционировать как самостоятельный (рис. 4).

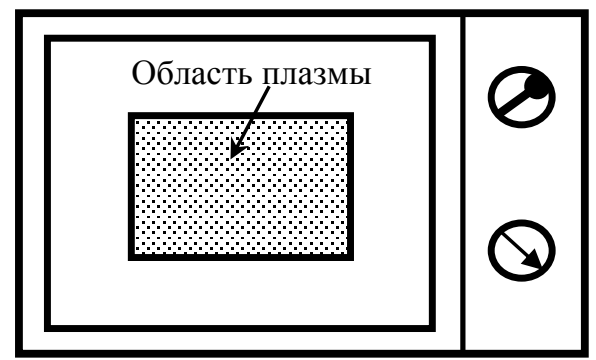

Рис. 4. Конфигурация плазменной области (передний план конвертированной в генератор плазмы СВЧ-печи).

С целью обеспечения максимально надежного розжига, а также гарантирования устойчивой работы генератора реакционно-активных форм кислорода при переменной нагрузке необходимо применить в микроволновой печи несамостоятельный СВЧ-разряд (то есть протекающий с использованием дополнительного ионизатора), непрерывно поддерживаемый специально подобранными ионизаторами, в т.ч. излучающими радионуклидами-эмиттерами. Дополнительным преимуществом при использовании радионуклидов является максимальная энергоэффективность генерации.

Радионуклиды, используемые при генерации холодной (нетепловой) плазмы, должны обладать рядом свойств: период полураспада $\left(t_{1 / 2}\right)$ эмиттера должен быть достаточно большим, чтобы обеспечить выделение энергии (ионизацию), причем с относительно постоянной скоростью, в течение разумного периода времени (в течение нескольких месяцев по крайней мере).

Кроме того, важна удельная мощность (измеряемая в Вт/г) - количество энергии, выделяемой (и расходуемой на ионизацию) за единицу времени единицей массы радионуклида. Плотность мощности (удельная мощность) обратно пропорциональна периоду полураспада и прямо пропорциональна энергии, выделяемой при каждом акте эмиссии данного радионуклида.

В табл. 2 перечислены наиболее подходящие радионуклиды для генерации плазмы. По сумме приведенных характеристик предпочтительным радионуклидом для генерации холодной плазмы следует признать изотоп полония Ро210. Особо привлекательной является его экстремально высокая удельная мощность (табл. 2:
$\left.P_{s} \sim 140 \mathrm{BT} / \Gamma\right)$, что гарантирует генерацию достаточно концентрированной (плотной) плазмы. Нанесение тонкого (по возможности - мономолекулярного) слоя Ро210 в качестве эмитирующей поверхности - обязательное условие для обеспечения высокой энергоэффективности за счет снижения бесполезных объемных тепловыделений. (Это связано с тем, что удельная мощность Ро210 чрезвычайно велика, и компактная капсула Ро210 массой всего 0,5 г при нормальных условиях достигает температуры свыше $500{ }^{\circ} \mathrm{C}$ из-за поглощаемой в объеме радионуклида кинетической энергии $\alpha$-частиц.) При нормальном атмосферном давлении в воздухе $\alpha$-частицы, излучаемые Ро210, полностью теряют свою энергию ( 5,49 МэВ) на пути в $\sim 4,14$ см (как это установил William H. Bragg). Эта характерная длина пути $\alpha$-частиц важна для оптимизации конструкций соответствующих аппликаторов.

На основе $\alpha$-излучения Ро210 легко получить плазму желаемой плотности - за счет простого наращивания площади эмитирующих поверхностей. Стоимость (доступность) радионуклидов для генерации холодной плазмы является решающим параметром для их широкого, экономически оправданного применения. Ро210 обычно производится искусственно - путем бомбардировки практически стабильного $\left(t_{1 / 2} \sim 1,9 \times 10^{19}\right.$ лет) изотопа висмута Вi209 нейтронами в ядерных реакторах:

$$
{ }_{83} \mathrm{Bi}^{209}+{ }_{0} n^{1}={ }_{83} \mathrm{Bi}^{210} .
$$

Затем радиоактивный $\operatorname{Bi2} 10$ в результате самопроизвольного $\beta$-распада (с периодом полураспада всего 5 дней) превращается в целевой Po210:

$$
{ }_{83} \mathrm{Bi}^{210}={ }_{84} \mathrm{Po}^{210}+\mathrm{e}^{-} .
$$

Этот способ получения и практического использования Ро210 для генерирования плазмы уже внедрен, но, по-видимому, он может быть дополнен. В стадии исследования - конкурирующий метод, основанный на возможности утилизации поступающего естественным образом из недр радиоактивного изотопа радона $\mathrm{Rn} 222$, с его последующим распадом до Ро210. Газообразный радон Rn222, обладающий периодом полураспада всего $t_{1 / 2} \sim 3,8$ дней, мигрирует от источника (из недр) к поверхности за счет диффузии, по пути большей частью распадаясь на более легкие изотопы других элементов. В итоге в атмосфере Земли находится лишь около $N_{A} \sim 6,02 \times 10^{23}$ атомов радона, располагающихся в приземном слое - из-за их большой массы. Динамическое равновесие поддерживается поступлением новых порций 
Таблица 2. Наиболее подходящие радионуклиды для генерации холодной плазмы

\begin{tabular}{|c|c|c|c|c|c|}
\hline $\begin{array}{l}\text { Радио- } \\
\text { нуклид }\end{array}$ & $\begin{array}{l}\text { Период полу- } \\
\text { распада }\left(t_{1 / 2}\right)\end{array}$ & $\begin{array}{l}\text { Удельная } \\
\text { мощность, } \\
\text { Вт/г }\end{array}$ & $\begin{array}{c}\text { Структура излучаемой } \\
\text { энергии }\end{array}$ & $\begin{array}{l}\text { Защитные } \\
\text { требования }\end{array}$ & $\begin{array}{c}\text { Способы } \\
\text { получения }\end{array}$ \\
\hline Po210 & 138,376 дней & 140 & $\begin{array}{c}\text { Практически чистый } \alpha \\
\text { изл. 5,49 МэВ (несуще- } \\
\text { ствен. } \gamma \text { или } \\
\text { рентгеновское изл.) }\end{array}$ & $\begin{array}{l}\text { Мини- } \\
\text { мальные }\end{array}$ & $\begin{array}{l}\text { Недра (включая } \\
\left.\text { извлечение } \mathrm{CH}_{4}\right) \\
\text { Реакторы ядерн. }\end{array}$ \\
\hline $\mathrm{Pu} 238$ & 87,6 лет & 0,568 & $\begin{array}{c}\text { Практически чистый } \alpha \\
\text { изл. (с низким } \\
\text { уровнем } \gamma \text { and } n) \\
\end{array}$ & $\begin{array}{c}\text { Мини- } \\
\text { мальные }\end{array}$ & Переработка ОЯТ \\
\hline Am241 & 432,2 лет & 0,114 & $\alpha$-излучение и $\gamma$ & Средние & Переработка ОЯТ \\
\hline $\mathrm{Sr} 90$ & 28,8 лет & 0,46 & $\begin{array}{c}\text { Практически чистый } \beta \text {, } \\
\text { но со вторич. тормоз. } \\
\text { излуч. }\end{array}$ & Высокие & Переработка ОЯТ \\
\hline Cs137 & 30,17 лет & $\sim 0,8$ & $\begin{array}{c}\beta \text {-изл. и } \\
\gamma \text { (не чистый } \beta \text { изл.) }\end{array}$ & $\begin{array}{l}\text { Макси- } \\
\text { мальные }\end{array}$ & Переработка ОЯТ \\
\hline
\end{tabular}

радона из глубины. Очевидно, что, добывая радон на глубине, можно одновременно снизить и остроту экологической проблемы. Радон и его производные являются ключевым фактором риска рака легких, в связи с чем Всемирная организация здравоохранения инициировала Международнылй радоновый проект (International Radon Project). Актуальная тема нейтрализации радона путем его утилизации выходит за рамки данной статьи.

Маски, защитные костюмы, перчатки и другие средства индивидуальной защиты от проникновения инфекций являются пассивными элементами. На основе окислительной неравновесной плазмы, создаваемой радионуклидами, возможна реализация портативной автономной активной системы обеззараживания вдыхаемого воздуха, предназначенной для безопасной работы персонала в зоне заражения.

Использование радионуклидов для генерации холодной плазмы является примером эффективного прямого преобразования ядерной энергии в высокопотенциальную энергию неравновесной плазмы.

Для варьирования в широких пределах производительности установок генерирования микроволновой плазмы и, соответственно, озона удобен модульный принцип генерирования (с наращиванием по мере надобности числа параллельно задействованных СВЧгенераторов).

На рис. 4 область плазмы ограничена аппликатором прямоугольной формы. Однако, при необходимости, для генерации плазмы может быть задействован весь полезный объем печи, в том числе для стерилизации в плазме термолабильных диэлектрических материалов, наряду с одновременным получением на выходе (относительно) стабильного озона - для его исполь- зования на месте или последующей транспортировки в другие места потребления.

Эффективность СВЧ-печи как плазменного стерилизатора может быть продемонстрирована на примере обеззараживания масок и респираторов. Синтетические материалы фильтров термолабильны, а моющие и дезинфицирующие средства вступают в химические реакции с полипропиленом, что повреждает фильтры и приводит к пропуску опасных мелких аэрозолей. Такой же эффект наблюдается при использовании кипячения, жесткой стирки, моющих и дезинфицирующих средств. Поэтому использование низкотемпературной окисляющей микроволновой плазмы для стерилизации таких материалов - оптимальный вариант, позволяющий добиться $100 \%$ стерильности за минимальное время. Следует только помнить о пожаробезопасности - температура нигде не должна превышать комнатную; это, в частности, означает, что металлический фиксатор для носа нельзя помещать в СВЧ-печь.

Реакции окисления - обязательно экзотермические, что означает возможность развития лавинообразного процесса горения, особенно на фоне роста температуры. Обращение с молекулярным кислородом как с потенциальным окислителем требует строгого соблюдения известных правил пожаробезопасности, среди которых - отсутствие пламени и искрений, достаточно низкая температура, отсутствие контакта с легковоспламеняющимися веществами, маслами и т.д. Однако генерация в кислородной плазме сильнейших окислителей (таких как атомарный кислород и озон) требует дополнительного анализа. Применяемая для деконтаминации - на удалении от плазмотрона концентрация озона не превышает 25-30 ppm. Это означает, что благодаря озонированию число реакционно-способных частиц в гипотетической 


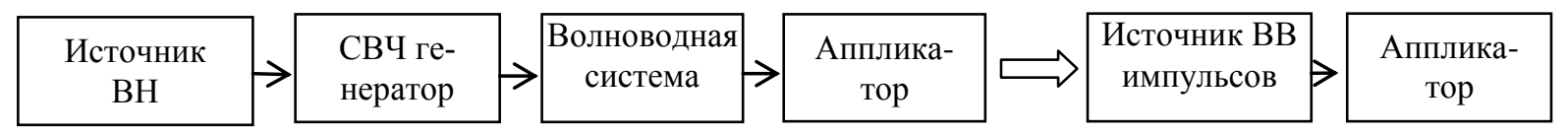

Рис. 5. Схема СВЧ плазменной установки в сравнении с высоковольтным импульсным вариантом.

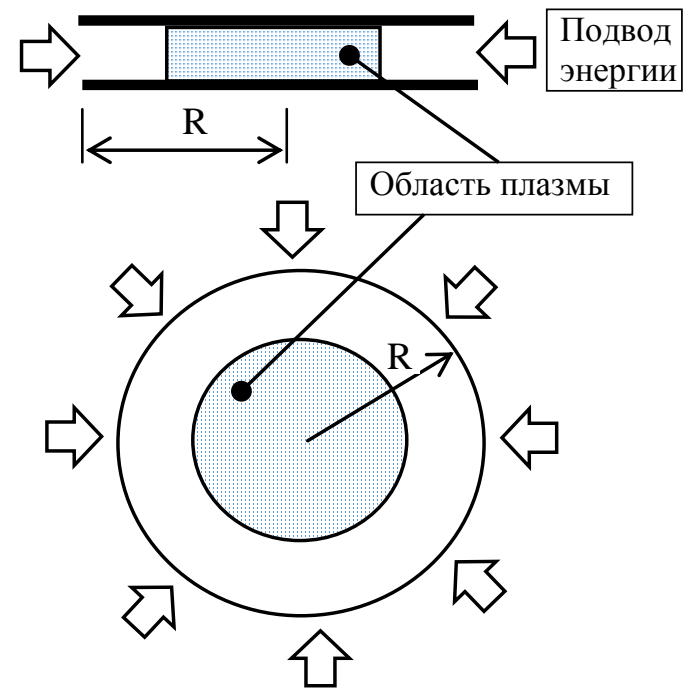

Рис. 6. В радиальной линии поглощение СВЧ-энергии плазмой компенсируется концентрацией поля.

зоне возгорания увеличивается всего на $(0,25-0,30) \times 10^{-6} \%$, что может оказать лишь ничтожно малое влияние на процесс воспламенения. Таким образом, меры пожаробезопасности при использовании озона для деконтаминации на удалении от плазмотрона мало отличаются от таковых при работе с молекулярным кислородом. Однако для недопущения возгорания обрабатываемых материалов в объеме плазмотрона крайне важно поддерживать достаточно низкую температуру газа (плазмы), которая является важнейшим фактором в плане предотвращения развития лавинообразного процесса горения. Добиться желаемой температуры плазмы можно, снижая различными способами температуру подаваемого газа (при необходимости - вплоть до криогенной).

Существенно, что Po210 - относительно легкоплавкий материал $\left(T_{\text {пл }} \sim 254{ }^{\circ} \mathrm{C}\right)-$ соответственно он не должен подвергаться воздействию повышенных температур.

Для генерации неравновесной (нетепловой) плазмы не обязательно использовать гармонические высокочастотные колебания. Такой же эффект можно получить в результате применения коротких (нано- и теоретически не исключено - пикосекундных) импульсов высокого напряжения. Импульсы высокого напряжения можно рассматривать как один и тот же (по сравнению с микроволнами) механизм действия, поскольку периодические наноимпульсы могут быть представлены как сумма осциллирующих функций, а именно $\sin (\omega t)$ и $\cos (\omega t)$ с частотами $\omega$ «микроволнового» диапазона (в результате их разложения в ряд Фурье). В случае применения наносекундных импульсов параметрами плазмы можно управлять через амплитуду, длительность и скважность импульсов. Основные отличия заключаются в конструкции оборудования (см. рис. 5).

На первый взгляд, «импульсный» вариант проще. Однако на сегодняшний день массовый, доведенный до совершенства «микроволновый» вариант превосходит «импульсный» - из-за сложности и дороговизны мощных импульсных высоковольтных источников (что не исключает изменения ситуации в будущем).

В плане генерации больших объемов однородной низкотемпературной микроволновой плазмы привлекательно применение радиальной линии, в которой поглощение СВЧ-энергии плазмой компенсируется сгущением силовых линий электрического поля по мере распространения волны к центру (см. рис. 6). Дополнительно регулировка напряженности СВЧ-поля осуществляется, при необходимости, корректировкой профиля радиальной линии. Применение радионуклидов в радиальном варианте также желательно, так как способствует энергоэффективности и устойчивости генерации.

Суммируя вышеприведенную информацию, следует констатировать: существует набор сертифицированных генераторов неравновесной плазмы относительно малой производительности, способных производить озон для деконтаминации воздушной среды и протяженных поверхностей. С целью повышения энергоэффективности обеззараживания (что 
особенно важно при больших объемах) необходимо доработать и сертифицировать перспективные микроволновые генераторы низкотемпературной плазмы и озона.

Озон, как оптимальный окислитель для деконтаминации, безусловно, должен использоваться в помещениях - в отсутствие людей - в концентрациях и при продолжительностях, гарантирующих 100\% обеззараживание. В этих случаях ограничения по концентрации и длительности применения озона обычно связаны с повреждаемостью чувствительных к окислению материалов (допустимая мольная доля определяется экспериментально, в первом приближении - около 25-30 ppm). Такие же жесткие режимы применимы при обеззараживании масок, одежды и других потенциально зараженных объектов. Многократное, безопасное и, при необходимости, безличное использование дорогостоящих защитных компонентов, инструментов и т.п. обеспечивает важный экономический эффект, который с минимальными затратами достигается благодаря окислению озоном.

У микроорганизмов нет (и, как обосновано выше, не может появиться) защиты от окисления озоном. В отличие от безоружных против озона всех живых существ, homo sapiens такую защиту может - при должном желании - создать. Благодаря абстрактному мышлению человек способен обеспечить необходимый для поддержания жизни прирост свободной энергии $\Delta G$ (что в данном конкретном случае означает создание эффективных средств борьбы с пандемией).

Для предотвращения вредного воздействия озона следует использовать именно его сильную сторону - высокую реакционную способность.

В отличие от классического противогаза, предлагается комплексная (раздельная) защита чувствительных к озону органов - глаз, носа и рта.

Для предохранения глаз достаточно применить изолирующие очки или специальные контактные линзы.

Наибольшую степень модернизации должна претерпеть защитная маска-респиратор. Полнолицевая защитная маска-респиратор, оснащенная угольными фильтрами, в большинстве случаев функционально избыточна и, соответственно, слишком дорогостояща при массовом применении. Следуя комплексному принципу массовой защиты, предлагается обеспечить, при необходимости, возможность самостоятельной (раздельной) защиты для носа и рта - очевидно, что это актуально (для менее уязвимого приема напитков, пищи и т.п.). Далее, маска-респиратор для дыхания через нос и рот должна быть агрегатной, то есть состоять из нескольких сменных слоев-масок. Внешняя (наружная) слой-маска, содержащая эффективные нейтрализаторы озона (и одновременно других отравляющих газов) на основе активированных углей, должна надеваться при входе в зоны с повышенным содержанием озона. В критической эпидемиологической ситуации такими зонами могут быть не только специализированные $C O V I D$-центры, но и торговые площади, транспорт и т.д. Вне зон озонирования желательно не пользоваться маской-нейтрализатором озона и сохранять ее расходный потенциал с помощью герметичной упаковки.

Ношение маски вызывает не только рост сопротивления дыханию, но и ухудшение качества вдыхаемого воздуха (во внутримасочном пространстве при выдохе остается определенная часть использованного воздуха с повышенным содержанием углекислого газа $\mathrm{CO}_{2}$ ). Кроме того, при пониженной температуре на маске может происходить конденсация влаги. Принципиальное решение указанных вопросов оптимально работает при низких температурах (так как сопровождается выделением тепла) и базируется на уникальном свойстве супероксидов (надпероксидов) накапливать и выделять кислород. В присутствии воды супероксиды поглощают выдыхаемый углекислый газ $\mathrm{CO}_{2}$ и обильно выделяют кислород $\mathrm{O}_{2}$. На примере супероксида калия $\mathrm{KO}_{2}$ суммарная реакция замещения углекислого газа $\mathrm{CO}_{2}$ на большее количество молекул кислорода $\mathrm{O}_{2}$ имеет вид:

$$
\begin{aligned}
& 4 \mathrm{KO}_{2}+2 \mathrm{CO}_{2}+\mathrm{H}_{2} \mathrm{O} \rightarrow \\
& \mathrm{H}_{2} \mathrm{O}+2 \mathrm{~K}_{2} \mathrm{CO}_{3}+3 \mathrm{O}_{2} .
\end{aligned}
$$

Внедрение данного метода обогащения вдыхаемого воздуха кислородом применительно к масочным респираторам облегчается тем, что указанный принцип конверсии углекислого газа в кислород уже используется на орбитальных станциях и субмаринах.

Совершенствование масок (респираторов) является субъектом повышенного внимания исследователей - во многом благодаря пандемии коронавируса $S A R S-C o V-2$. Дан старт разработке и внедрению интеллектуальной маски [63] своеобразной $i$-mask, - позволяющей установить наличие коронавируса $S A R S-C o V-2$ в организме носителя. Функции интеллектуальной маски, безусловно, будут расширяться. Например, остро стоит вопрос оперативной экспресс-диагностики концентрации коронавируса в воздухе - как в критических помещениях, так и в свободных пространствах.

Астрономическое количество произведенных масок требует их адекватной утилизации. По нашему мнению, оптимальным способом 

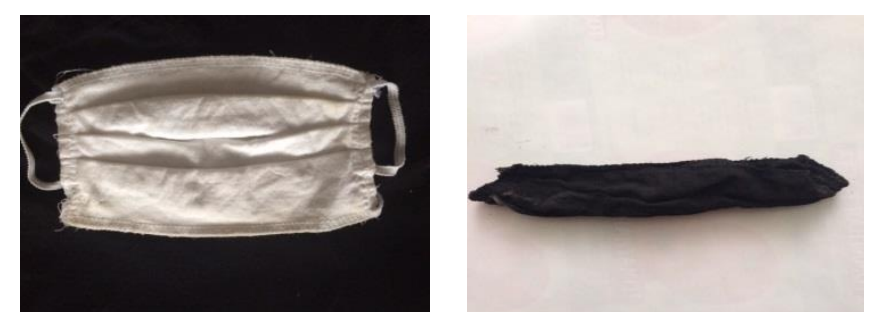

Рис. 7. Слева - маска б/у из хлопчатобумажной ткани; справа - та же маска, подвергнутая пиролизу при $t \sim 900{ }^{\circ} \mathrm{C}$ в цилиндрическом аппликаторе.

Рис. 8. Тонкопленочный балластный сосуд, заполненный стерильным газом.

утилизации израсходованных масок является их высокотемпературный пиролиз, с дальнейшей утилизацией активированного угля (в т.ч. для изготовления новых масок), а также остаточных углеводородов (см. рис. 7). Высокие температуры гарантируют микробиологическую безопасность продуктов пиролиза - независимо от характера и степени их загрязнения.

Пандемия коронавируса $S A R S-C o V-2$ выявила недочеты и диктует необходимость совершенствования мер микробиологической безопасности на всех уровнях, включая бытовой.

Например, в медицине для внутривенного вливания традиционно используются инфузионные системы (капельницы), в которых предусмотрено замещение вводимой в вену жидкости воздухом, забираемым непосредственно из помещения. Такая практика неприемлема в условиях пандемии, так как коронавирус, с определенной вероятностью присутствующий в любом помещении, получает возможность беспрепятственного попадания непосредственно в кровь пациента, провоцируя нозокомиальное (внутрибольничное) инфицирование. Решение данной проблемы возможно многими способами, в том числе путем применения фильтра на базе низкотемпературной плазмы. Однако более доступным и оперативным представляется применение тонкопленочного балластного сосуда, заполненного стерильным газом (см. рис. 8). Таким газом может быть доступный в больничных условиях медицинский кислород, поступление которого непосредственно в кровь не просто безвредно, а обычно даже благотворно.

Пандемия коронавируса акцентировала важность модернизации систем кондиционирования воздуха в помещениях.
Для гарантированного обеспечения микробиологической безопасности широко применяемые централизованные системы кондиционирования должны быть дополнены средствами надежной деконтаминации - как для свежего приточного воздуха, так и для загрязненного вытяжного, сбрасываемого в атмосферу. При этом следует отметить, что централизованные системы кондиционирования инерционны и не способны оперативно реагировать на резкие изменения погоды, контингента и вирусной нагрузки в конкретных критических местах. Поэтому такие места (операционные, приемные отделения больниц, залы ожидания и т.п.) должны располагать маневренной локальной системой кондиционирования, совмещенной с контролируемой (управляемой) деконтаминацией. При оптимальном варианте, по нашему мнению, на крупных объектах централизованно должна обеспечиваться лишь базовая нагрузка, с обязательной возможностью коррекции кондиционирования локальными средствами.

Очевидно, что в локальных системах кондиционирования проще учитывать вирусную нагрузку (наряду с прочими факторами местного характера) и, при необходимости, варьировать параметры кондиционирования и интенсивность обеззараживания. Но термин «локальная система» не означает, что допустима ее замкнутость (практически замкнутыми, без существенного обновления воздуха, являются сплитсистемы). Имманентным недостатком сплитсистем является рециркуляция внутреннего воздуха при отсутствии должного притока свежего наружного воздуха (равно как и удаления загрязненного). Локальные сплит- 
системы кондиционирования - даже оснащенные фильтрами и холодной плазмой - категорически противопоказаны учреждениям с многочисленным контингентом (больницам, школам, библиотекам и т.д.). Для таких объектов необходимы энергетически оптимизированные системы кондиционирования с адекватно высокой кратностью воздухообмена и контролируемой деконтаминацией приточного и удаляемого воздуха. Создание таких систем - это без преувеличения один из самых жизненно важных вызовов, тесно связанный с энергетикой и экологией и дополнительно стимулируемый активизацией микробиологических угроз. Отметим, что в рамках сформулированной комплексной проблемы задача (компонента) обеззараживания при кондиционировании решается, как отмечено выше, употреблением низкотемпературной («холодной») плазмы для энергоэффективной генерации реакционно-активных форм кислорода. Фильтрация пыли из воздуха до деконтаминации важна не только в плане кондиционирования, но и для снижения окислительной нагрузки (органические частицы пыли обычно потребляют существенное количество окислителя).

Критическая эпидемиологическая ситуация, сложившаяся в связи с пандемией $S A R S-C o V-2$, обусловила акцент в данной работе в основном на обеззараживание протяженных и удаленных объектов. Однако рассмотренные оптимальные методы и средства обеззараживания применимы не только в медицине, но также могут быть адаптированы для многочисленных применений в сельском хозяйстве, промышленности и в быту. Такие, обычно компактные, приложения позволяют в полной мере реализовать арсенал окислительной низкотемпературной («холодной») плазмы - возможность вариации состава плазмообразующих газов, поддержания оптимального давления (вакуума) и температуры в аппликаторе, сочетания деконтаминации с досушкой и т.д.

\section{ВЫВОДЫ}

Оптимизация микробиологической деконтаминации, с учетом неизбежной перспективы появления новых эпидемических угроз, представляется приоритетной задачей. Необратимые химические реакции окисления служат кратчайшим способом достижения стерильности при максимальной надежности деконтаминации. При этом кислород оптимален в качестве окислителя, в том числе экологически, так как он и все его реакционно-активные формы гармонично вписываются в естественные циклы обмена. Оптимальным путем получения реакционно-активных форм кислорода для обеззараживания является применение низкотемпературной («холодной») плазмы, обеспечивающей энергоэффективную генерацию окислительных реакционно-активных форм: атомарного кислорода $(\mathrm{O})$, озона $\left(\mathrm{O}_{3}\right)$, гидроксильного радикала (·OH), перекиси водорода $\left(\mathrm{H}_{2} \mathrm{O}_{2}\right)$, супероксида $\left(\mathrm{O}_{2}^{-}\right)$, синглетного кислорода $\mathrm{O}_{2}\left(a^{1} \Delta_{g}\right)$. Из-за короткого времени жизни большинства вышеназванных форм вне плазменного аппликатора удаленные от генератора плазмы объекты стерилизуются озоном $\left(\mathrm{O}_{3}\right)$ - его минимальное время жизни достаточно велико (измеряется минутами). Для энергоэффективного производства озона оптимален микроволновый способ генерации кислородной плазмы.

При обширном загрязнении поверхностей целесообразно - дополнительно к обеззараживающему воздух озону $\left(\mathrm{O}_{3}\right)$ - применение водных растворов перекиси водорода $\left(\mathrm{H}_{2} \mathrm{O}_{2}\right)$. Немаловажно, что эти реакционно-активные формы кислорода для обеззараживания удаленных от генератора плазмы объектов обладают высокой эффективностью и при этом экологически безвредны.

Для исключения какого-либо ущерба человеческому организму при применении озона актуален вопрос доработки и сертификации современной полифункциональной маскиреспиратора. Не менее актуальны энергоэффективные системы кондиционирования с адекватной деконтаминацией аспирационного и использованного воздуха.

Рассмотренные оптимальные средства обеззараживания применимы не только в медицинской практике, но также могут быть адаптированы для многочисленных модернизаций в сельском хозяйстве, промышленности и в быту.

Следует подчеркнуть, что никакие микроорганизмы не могут противостоять уничтожающему воздействию озона и других окислительных компонентов низкотемпературной плазмы.

\section{ФИНАНСИРОВАНИЕ РАБОТЫ}

Работа выполнена в рамках Государственной программы: Интенсификация процессов переноса и обработки в электрических, электромагнитных, кавитационных полях; применимость. ANCD 20.80009.5007.06 (2020-2023).

\section{КОНФЛИКТ ИНТЕРЕСОВ}

Авторы заявляют, что у них нет конфликта интересов. 


\section{ЛИТЕРАТУРА}

1. Menebo, M.M., Temperature and precipitation associate with Covid-19 new daily cases: A correlation study between weather and Covid-19 pandemic in Oslo, Norway, Sci. Total Environ., 2020, vol. 737, art. ID 139659. https://doi.org/10.1016/j.scitotenv.2020.139659.

2. Vinoj, V., Gopinath, N., Landu, K., Behera, B., et al., The COVID-19 spread in India and its dependence on temperature and relative humidity, Preprints, 2020, 2020070082 (doi: 10.20944/preprints202007.0082.v1).

3. Rahimi, N.R., Fouladi-Fard, R., Aali, R., Shahryari, A., et al., Bidirectional association between COVID-19 and the environment: A systematic review, Environ. Res., 2021, vol. 194, art. ID 110692, doi: 10.1016/j.envres.2020.110692.

4. Dbouk, T. and Drikakis, D., Weather impact on airborne coronavirus survival, Phys. Fluids, 2020, vol. 32, art. $\quad$ ID 093312 . https://doi.org/10.1063/5.0024272

5. Bhardwaj, R. and Agrawal, A., Likelihood of survival of coronavirus in a respiratory droplet deposited on a solid surface, Phys. Fluids, 2020, vol. 32, art. ID 061704.

6. Hridoy, A.E.E., Mohiman, M.A., Tusher, S.M.S.H., Nowraj, S.Z.A., et al., Impact of meteorological parameters on COVID-19 transmission in Bangladesh: a spatiotemporal approach, Theor. Appl. Climatol., 2021, vol. 144, no. $1-2$, p. 273. https://doi.org/10.1007/s00704-021-03535-x

7. Callaway, E., The coronavirus is mutating - does it matter? Nature, 2020, vol. 585, no. 7824, p. 174. https://doi.org/10.1038/d41586-020-02544-6

8. Xiang, J., Wan, Ch., Guo, R., and Guo, D., Is hydrogen peroxide a suitable apoptosis inducer for all cell types? BioMed Research International, 2016, vol. 2016, art. ID 7343965, https:// doi.org/10.1155/2016/7343965.

9. Химическая энциклопедия, Изд-во «Большая Российская Энциклопедия», М.: 1998.

10. Рабинович, В.А., Хавин, З.Я., Краткий химический справочник, 3-е изд., Изд-во «Химия», СПб, 1991.

11. Tantardini, Ch. and Oganov, A.R., Thermochemical electronegativities of the elements, Nat. Commun, 2021, vol. 12, art. ID 2087. https://doi.org/10.1038/s41467-021-22429-0

12. Kawaguchi, Yu., Shibuya, M. Kinoshita, Io., Yatabe, Yu. et al., DNA damage and survival time course of deinococcal cell pellets during 3 years of exposure to outer space, Front. Microbiol, 2020, vol. 11, art. ID 2050. doi: 10.3389/fmicb.2020.02050

13. Ye, D., Li, J. and Tang, J., Jet propulsion by microwave air plasma in the atmosphere, AIP Advances, 2020, vol. 10, art. ID. 055002. https://doi.org/10.1063/5.0005814
14. Misra, N.N., Patil, S., Moiseev, T., Bourke, P., et al., In-package atmospheric pressure cold plasma treatment of strawberries, J. Food Eng., 2014, vol. $125, \quad$ p. 131. https://doi.org/10.1016/j.jfoodeng.2013.10.023

15. Rogez-Kreuz, C., Yousfi, R., Soufflet, C., Quadrio, I., et al., Inactivation of animal and human prions by hydrogen peroxide gas plasma sterilization, Infec. Control Hosp. Epidemiol. 2009, vol. 30, no. 8, p. 769.

16. Pekárek, S., Non-Thermal Plasma Ozone Generation, Acta Polytech., 2003, vol. 43, no. 6, p. 47.

17. Law, V.J. and Dowling, D.P., Converting a microwave oven into a plasma reactor: A Review, Intl. J. Chem. Eng., 2018, vol. 2018, art. ID 2957194. https://doi.org/10.1155/2018/2957194.

18. De la Fuente, J.F., Kiss, A.A., Radoiu, M.T. and Stefanidis, G.D., Microwave plasma emerging technologies for chemical processes, J. Chem. Technol. Biotechn., 2017, vol. 92, no. 10, p. 2495. https://doi.org/10.1002/jctb.5205.

19. Sun, B., Zhang, L. and Sato, M., Characteristics of atomic oxygen produced by a pulsed streamer corona discharge, Int. J. Environ. Waste Manag., 2008, vol. 2, no. 4-5, p. 447.

20. Moisan, M., Barbeau, J., Crevier, M.-Ch., Pelletier, J., et al., Plasma sterilization. Methods and mechanisms, Pure Appl. Chem., 2002, vol. 74, no. 3, p. 349.

21. Moisan, M., Barbeau, J., Moreau, S., Pelletier, J., et al., Low-temperature sterilization using gas plasmas: a review of the experiments and an analysis of the inactivation mechanisms, Intern. J. Pharm., 2001, vol. 226, no. 1-2, p. 1.

22. Berezhetskaya, N.K., Gritsinin, S.I., Kop'ev, V.A., Kossyi I.A., et al., Long-lived plasmoids generated by surface microwave discharges in chemically active gases, Plasma Phys. Rep., 2005, vol. 31, p. 886. https://doi.org/10.1134/1.2101976

23. Shimizu, T., Steffes, B., Pompl, R., Jamitzky, F., et al., Characterization of microwave plasma torch for decontamination, Plasma Process Polym., 2008, vol. 5, p. 577.

24. Chau, T.T., Kao, K.C., Blank, G. and Madrid, F., Microwave plasmas for low-temperature dry sterilization, Biomaterials, 1996, vol. 17, no. 13, p. 1273.

25. Lerouge, S., Wertheimer, M.R. and Yahia, L.H., Plasma sterilization: a review of parameters, mechanisms, and limitations, Plasmas Polym., 2001, vol. 6, no. 3, p. 175.

26. Hati, S., Mandal, S., Vij, S., Minz, P.S., et al., Nonthermal plasma technology and its potential applications against foodborne microorganisms, J. Food Process. Preserv., 2012, vol. 36, no. 6, p. 518.

27. Jerby, E., Meir, Ye., Jaffe, R. and Jerby, I., Food cooking by microwave-excited plasmoid in air 27. Atmosphere, Proceedings of 14 th International Conference on Microwave and High Frequency Heating, AMPERE-2013, Nottingham, UK, 2013, p. 17. 
28. Kogelheide, F., Voigt, F., Hillebrand, B., Moeller, R., et al., The role of humidity and UV-C emission in the inactivation of $B$. subtilis spores during atmosphericpressure dielectric barrier discharge treatment, J. Phys. D: Appl. Phys., 2020, vol. 53, art. ID.295201. https://doi.org/10.1088/1361-6463/ab77cc

29. Myers Brayden, Pietro Ranieri, Tatyana Smirnova, Patrick Hewitt, et al., Measuring plasma-generated - $\mathrm{OH}$ and $\mathrm{O}$ atoms in liquid using EPR spectroscopy and the non-selectivity of the HTA assay, Journal of Physics D: Applied Physics, 2021, vol. 54, no. 14, ID.145202, https://doi.org/10.1088/1361-6463/abd9a6

30. Laroussi, M., Lu, X. and Keidar, M., Perspective: The physics, diagnostics, and applications of atmospheric pressure low temperature plasma sources used in plasma medicine, J. Appl. Phys., 2017, vol. 122, no. 2, p. 020901. WOS:000405663800001.

31. Bruggeman, P.J., Iza, F. and Brandenburg R., Foundations of atmospheric pressure non-equilibrium plasmas, Plasma Sources Sci. Technol., 2017, vol. 26, no. 12, art. ID 123002. WOS:000425761500001.

32. Baldus, S., Schroder, D., Bibinov, N., Schulz-von der Gathen V., et al., Atomic oxygen dynamics in an air dielectric barrier discharge: a combined diagnostic and modeling approach, J. Phys. D Appl. Phys., 2015, vol. 48, no. 27, p. 275203. WOS:000356625900011.

33. Brandenburg, R., Dielectric barrier discharges: progress on plasma sources and on the understanding of regimes and single filaments, Plasma Sources Sci. Technol., 2017, vol. 26, no. 5, p. 053001. WOS:000398259600001.

34. Sousa, J., Niemi K., Cox, L., Algwari, Q.T., et al., Cold atmospheric pressure plasma jets as sources of singlet delta oxygen for biomedical applications, J. Appl. Phys., 2011, vol. 109, no. 12, p. 123302.

35. Weltmann, K.D. and von Woedtke, T., Plasma medicine-current state of research and medical application, Plasma Physics and Controlled Fusion, 2017, vol. 59, no. 1, p. 014031. WOS:000387795200006.

36. Ruiling Lv, Donghong Liu and Jianwei Zhou, Bacterial spore inactivation by non-thermal technologies: resistance and inactivation mechanisms, Current Opinion in Food Science, December 2021, vol. 42 , p. 31 .

37. David B. Graves, Low temperature plasma biomedicine: A tutorial review, Physics of Plasmas, 2014, vol. 21, no. 8, p. 080901. https://doi.org/10.1063/1.4892534

38. John E. Foster, Plasma-based water purification: Challenges and prospects for the future, Physics of Plasmas, 2017, vol. 24, no. 5, p. 055501. https://doi.org/10.1063/1.4977921

39. Laroussi, M. and $\mathrm{Lu} \mathrm{X.,} \mathrm{Room-temperature}$ atmospheric pressure plasma plume for biomedical applications, Applied Physics Letters, 2005, vol. 87, no. 11, p. 113902.

40. Andrei Cristian Ionescu, Eugenio Brambilla, Lamberto Manzoli, Giovanna Orsini, et al., Aerosols modification with $\mathrm{H}_{2} \mathrm{O}_{2}$ reduces airborne contamination by dental handpieces, Journal of Oral Microbiology, vol. 13, no. 1, p. 1881361. doi: 10.1080/20002297.2021.1881361

41. Basaran, P., Basaran-Akgul, N. and Oksuz, L., Elimination of Aspergillus parasiticus from nut surface with low pressure cold plasma (LPCP) treatment, Food Microbiol., 2008, vol. 25, no. 4, p. 626.

42. Th von Woedtke, Reuter S., Masura K. and Weltmann K.-D., Plasmas for medicine, Phys. Rep., 2013, vol. 530, no. 4, p. 291.

43. Zhitong Chen, Gustavo Garcia, Vaithilingaraja Arumugaswami and Richard E. Wirz, Cold atmospheric plasma for SARS-CoV-2 inactivation, Phys. Fluids., 2020, vol. 32, no. 11, p. 111702. https://doi.org/10.1063/5.0031332

44. Sarojini Tiwari, Ashley Caiola, Xinwei Bai, Amoolya Lalsare, et al., Microwave plasma-enhanced and microwave heated chemical reactions. A Review, Plasma Chemistry and Plasma Processing, 2020, vol. 40, no. 1, p. 1, doi: 10.1007/s11090-019-10040-7

45. Domonkos, M., Tichá, P., Trejbal, J. and Demo, P., Applications of cold atmospheric pressure plasma technology in medicine, agriculture and food industry, Appl. Sci., 2021, vol. 11, no. 11, p. 4809. https://doi.org/10.3390/app11114809

46. Uroš Cvelbar, James Walsh, Mirko Černák, Hindrik de Vries, Stephan Reuter, et al.. White paper on the future of plasma science and technology in plastics and textiles. Plasma Processes and Polymers, WileyVCH Verlag, 2019, vol. 16, no. 1, p. 1700228. $\langle 10.1002 /$ ppap.201700228〉. 〈hal-02105352〉

47. Nicolas Monrolin, Franck Plouraboué, Olivier Praud. Electrohydrodynamic thrust for in-atmosphere propulsion. AIAA Journal, American Institute of Aeronautics and Astronautics, 2017, vol. 55, no. 12, p. 4296. 〈10.2514/1.J055928〉. 〈hal-01660600〉

48. Miotk, R., Hrycak, B., Czylkowski, D., Dors, M., et al., Liquid fuel reforming using microwave plasma at atmospheric pressure, Plasma Sources Sci. Technol., 2016, vol. 25, no. 11, p. 035022.

49. Uhm, H.S., Kim, J.H. and Hong, Y.C., Disintegration of water molecules in a steam-plasma torch powered by microwaves, Phys. Plasmas., 2007, vol. 14, p. 073502.

50. Uhm, H.S., Hong, Y.C. and Shin, D.H., A microwave plasma torch and its applications, Plasma Sources Sci. Technol., 2006, vol. 15, no. 2, p. S26.

51. Xu, H., He, Y., Strobel, K.L., Gilmore, C.K., et al., Flight of an aeroplane with solid-state propulsion, Nature, 2018, vol. 563, no. 7732, p. 532.

52. Ali A. Isikber and Christos G. Athanassiou, The use of ozone gas for the control of insects and microorganisms in stored products, Journal of Stored Products Research, 2014, vol. 64, p. 139. doi: 10.1016/j.jspr.2014.06.006

53. Megahed, A., Aldridge, B. and Lowe, J., The microbial killing capacity of aqueous and gaseous ozone on different surfaces contaminated with dairy 
cattle manure, PLoS ONE, 2018, vol. 13, no. 5, p. e0196555. https://doi.org/10.1371/journal.pone.0196555

54. Физическая эничиклопедия. Изд-во «Большая Российская Энциклопедия», М.: 1998, т. 5.

55. Смышляев, С.П., Гонцов, Я.А., Хорева, Е.И., Оценки времени нахождения в атмосфере химически-активных антропогенных газов, Ученые записки Российского государственного гидрометеорологического университета, 2011, № 22, c. 195.

56. Taneja, N., Biswal M., Kumar A., Edvin A., et al., Hydrogen peroxide vapour for decontaminating air-conditioning ducts and rooms of an emergency complex in northern India: time to move on, J. Hosp. Infect., 2011, vol. 78, no. 3, p. 200. doi: 10.1016/j.jhin.2011.02.013. Epub 2011.

57 Falagas,

M.E., Thomaidis

P.C.,

Kotsantis I.K., Sgouros K., et al., Airborne hydrogen peroxide for disinfection of the hospital environment and infection control: a systematic review, J. Hosp. Infect., 2011, vol. 78, no. 3, p. 171. doi: 10.1016/j.jhin.2010.12.006. Epub 2011.

58. Pottage, T., Richardson, C., Parks, S., Walker, J.T., et al., Evaluation of hydrogen peroxide gaseous disinfection systems to decontaminate viruses, J. Hosp. Infect., 2010, vol. 74, no. 1, p. 55. doi: 10.1016/j.jhin.2009.08.020. Epub 2009 Nov 20. PMID: 19931937

59. Daniel Kiser, Gai Elhanan, William J. Metcalf, Brendan Schneider, et al., SARS-CoV-2 test positivity rate in Reno, Nevada: association with PM2.5 during the 2020 wildfire smoke events in the western United States, Journal of Exposure Science \& Environmental Epidemiology; 2021, vol. 31, p. 797. https://doi.org/10.1038/s41370-021-00366-w .

60. Azharonok V., Filatova I., Bosneaga Iu., Bologa M., et al., Non-thermal plasma sterilization in RF and MW discharges, Romanian Journal of Physics, 2011, vol. 56, Supplement, p. 62.

61. Bosneaga, Iu., Bologa, M. and Agarwal, E., Intensification of electro-magneto-hydrodynamic effects using radionuclides, Proceedings of 12-th International Conference on Modern Problems of Electrophysics and Electrohydrodynamics (MPEE-2019), Russia, Peterhof, 2019, p. 189.

62. Bernard M. Babior, Cindy Takeuchi, Julie Ruedi, Abel Gutierrez, et al., Investigating antibodycatalyzed ozone generation by human neutrophils, Proceedings of the National Academy of Sciences of the United States of America (PNAS), 2003, vol. 100, no. 6, p. 3031. https://doi.org/10.1073/pnas.0530251100

63. Peter Q. Nguyen, Luis R. Soenksen, Nina $M$. Donghia, Nicolaas M. Angenent-Mari, et al., Wearable materials with embedded synthetic biology sensors for biomolecule detection, Nature Biotechnology, 2021, vol. 39, p. 1366. https://doi.org/10.1038/s41587-021-00950-3

\section{Summary}

Modern civilization, providing economic and social progress, at the same time objectively creates - sometimes close to ideal - conditions for the spread of various infections. The catastrophic consequences of the SARS-CoV-2 pandemic clearly indicate that homo sapiens appeared to be unable to resist effectively the onslaught of the coronavirus. The purpose of this publication is an attempt to fill the gap in the development of effective methods and means for microbiological decontamination that are optimal in terms of critical parameters. Observational data indicate that a significant number of SARS-CoV-2 coronavirus infections occur by air without a direct contact with the source, including, over a long time interval. Precipitations help to cleanse the air from pollutants and viruses, reducing non-contact contamination, which additionally brings up to date the problem of optimal microbiological decontamination of the air environment and surfaces. A thermodynamic approach has been used to optimize microbiological sterilization. It is shown that irreversible chemical oxidation reactions are the shortest way to achieve sterility, and they are capable of providing high reliability of decontamination. It has been established that oxygen is an optimal oxidant, also from the point of view of ecology, since its reactive forms harmoniously fit into natural exchange cycles. The optimal method for obtaining reactive oxygen species for disinfection is the use of lowtemperature ("cold") plasma, which provides energyefficient generation of oxidative reactive forms - atomic oxygen $(\mathrm{O})$, ozone $\left(\mathrm{O}_{3}\right)$, hydroxyl radical $(\cdot \mathrm{OH})$, hydrogen peroxide $\left(\mathrm{H}_{2} \mathrm{O}_{2}\right)$, superoxide $\left(\mathrm{O}_{2}{ }^{-}\right)$, and singlet oxygen $\mathrm{O}_{2}\left(a^{1} \Delta_{g}\right)$. Due to a short lifetime for most of the above forms outside the plasma applicator, remote from the plasma generator objects should be sterilized with ozone $\left(\mathrm{O}_{3}\right)$, the minimum lifetime of which is quite long. It has been substantiated that the microwave method of generating oxygen plasma is optimal for the energy efficient ozone production. A modular principle of generation is proposed for varying the productivity of ozone generating units over a wide range. The module has been developed on the base of an adapted serial microwave oven, in which a non-self-sustaining microwave discharge is maintained thanks to ionizers (igniters), including those based on radiating radionuclides-emitters. In case of massive contamination of surfaces, it is advisable - in addition to ozone $\left(\mathrm{O}_{3}\right)$ air disinfecting - to use aqueous solutions of hydrogen peroxide $\left(\mathrm{H}_{2} \mathrm{O}_{2}\right)$. It is essential that these reactive oxygen species for disinfecting remote from the plasma generator objects are highly efficient and, at the same time, environmentally neutral. Reliable and affordable personal protective equipment is proposed for activities in zones of increased ozone concentration. The considered optimal means of disinfection can be applicable not only in medicine, but also adapted for numerous practices in agriculture, industry, and in everyday life.

Keywords: coronavirus, optimization of microbiological sterilization, thermodynamic approach, reactive oxygen species, low-temperature plasma, ozone, hydrogen peroxide, microwaves 